\title{
Microbiome-Gut-Brain-Axis communication influences metabolic switch in the mosquito Anopheles culicifacies
}

Tanwee Das De ${ }^{1 \$}$, Punita Sharma ${ }^{1 \$}$, Sanjay Tevatiya ${ }^{1}$, Charu Chauhan ${ }^{1}$, Seena Kumari ${ }^{1}$, Deepak Singla ${ }^{1,2}$, Vartika Srivastava ${ }^{1}$, Jyoti Rani ${ }^{1}$, Yasha Hasija ${ }^{3}$, Kailash C Pandey ${ }^{1}$, Mayur Kajla ${ }^{1}$ and Rajnikant Dixit ${ }^{1 *}$.

${ }^{1}$ Laboratory of Host-Parasite Interaction Studies, National Institute of Malaria Research, Sector-8, Dwarka, Delhi 110077, India.

${ }^{2}$ School of Agricultural Biotechnology, Punjab Agricultural University, Ludhiana, Punjab, India.

${ }^{3}$ Department of Biotechnology, Delhi Technological University. Shahbad Daulatpur, Main Bawana Road, Delhi-110042, India

\$ Authors equally contributed

*Author for correspondence (dixitrk@mrcindia.org)

\begin{abstract}
:
Periodic ingestion of a protein-rich blood meal by adult female mosquitoes causes a drastic metabolic change in their innate physiological status, which is referred to as 'metabolic switch. Although the down-regulation of olfactory factors is key to restrain host-attraction, how the gut 'metabolic switch' modulates brain functions, and resilience physiological homeostasis remains unexplored. Here, we demonstrate that the protein-rich diet induces mitochondrial function and energy metabolism, possibly shifting the brain's engagement to manage organismal homeostasis. A dynamic expression pattern of neuro-signaling and neuromodulatory genes in both the brain and gut indicates an optimal brain-distant organ communication. Even after decapitation, significant modulation of the neuro-modulator receptor genes as well as quantitative estimation of neurotransmitters (NTs), together confer the gut's ability to serve as a 'second brain'. Finally, data on comparative metagenomic analysis and altered NTs dynamics of naïve and aseptic mosquitoes provide the initial evidence that gut-endosymbionts are key modulators for the synthesis of major neuroactive molecules. Conclusively, our data establish a new conceptual understanding of microbiome-gut-brain-axis communication in mosquitoes.
\end{abstract}

Keywords: Mosquito, brain, metabolic switch, gut, blood-feeding, gut-brain-axis communication, symbionts, cognition. 


\section{Graphical abstract:}

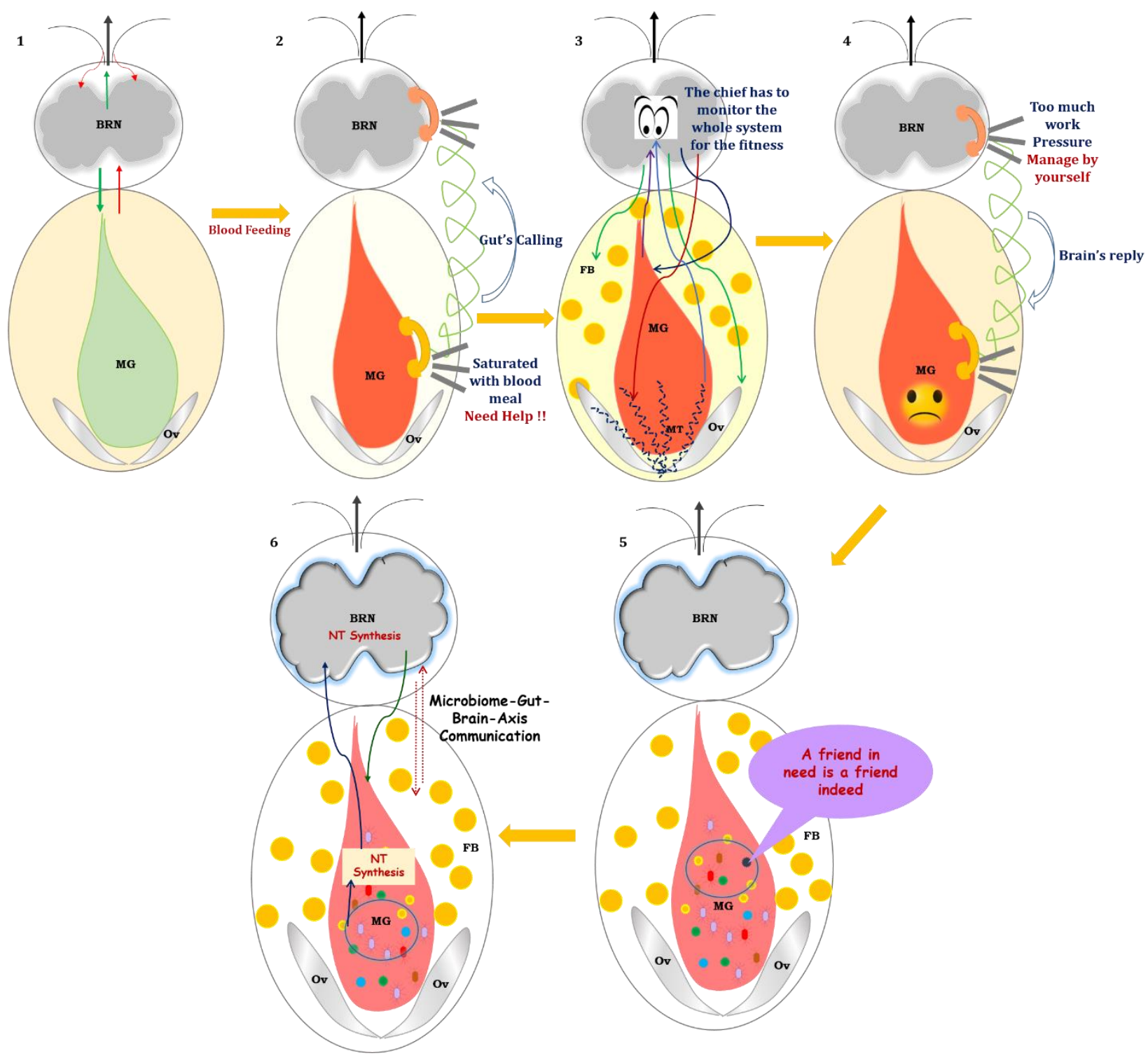

\section{Highlights:}

- Highly proteinaceous blood meal uptake causes gut 'metabolic switch' activity in mosquitoes.

- Gut's calling shifts the brain's administrative function from external communication to inter-organ management.

- 'Gut', as a 'Second brain' plays a crucial role in the maintenance of physiological homeostasis.

- Metabolic switch and proliferation of symbiotic bacteria establish microbiome-gutbrain axis communication in mosquitoes. 


\section{Introduction}

The brain is a privileged organ in shaping an animal's behavior from lower to higher taxa by guiding and managing the diverse nature of external and internal stimuli. While each and every behavior of any organism is finely orchestrated by multiple organs, it is the brain that directs and exchange decision-making actions to regulate distinct organs functions. Unlike the human brain, which hosts billions of neurons, it is important to understand how insect's especially blood-feeding mosquitoes having less than 1,00,000 neurons in their tiny brain, regulate similar functions such as finding a suitable source for sugar feeding and blood-feeding, searching for a mate-partner, and locating a proper oviposition site for egg-laying, etc. Decades of research have revealed that the molecular interaction of olfactory derived odorant-binding proteins (OBPs) and olfactory receptors (Ors) with the environmental chemical cues (external cues), play a central role in initializing these behaviors $[1,2]$. However, successful completion of these behavioral activities is also influenced by the innate physiological status of the mosquitoes such as satiated/starved, mated/unmated, nutritional status, gravid, or not[3]. Thus how the miniature brain of mosquitoes harmonizes internal and external cues and affects decisionmaking abilities, is yet unknown.

Upon locating a suitable vertebrate host, a positive feeding decision stimulates the salivary glands of the adult female mosquito to facilitate rapid blood meal ingestion, and temporarily arrest olfactory actions until $30 \mathrm{~h}$ of blood-feeding[1]. Although, a fully engorged female mosquito shows a dramatic suppression of host-seeking until the eggs are laid ( $72 \mathrm{~h}$ post blood meal), however, the reactivation of the peripheral sensory system (30-40h post blood meal) is necessary to accompany complex oviposition site finding behavioral activities and gonotrophic cycle completion[4, 5]. A recent study by Duvall et. al. indicates that activation of Neuropeptide Y (NPY) signaling is essential for the suppression of host-seeking behavior for several days after blood feeding[4]. However, we have limited knowledge of how the mosquito's brain regulates the binary behavioral switch responses (sugar to blood-feeding), and maintain organismal physiology in blood-fed females.

Fast engorgement of the mosquito's gut with blood causes a drastic metabolic change in the innate physiological status from sugar to a protein-rich diet, resulting in the alteration of cellular fuel sources. This 'metabolic switch' drives multiple organs' engagement to perform respective functions, such as osmoregulation by Malpighian tubules, progressive blood meal digestion by the gut, nutrient mobilization, and activation of vitellogenesis in the fat body, and ovary development for egg maturation[6-11]. The central nervous system should establish and maintain inter-organ communication to manage the sequential event of mosquitoes' inner physiological activities. Several neuromodulators, such as neuropeptides, neurotransmitters, and neurohormones having a role in neuro-synaptic signal transmission and inter-organ communication, have been characterized in fruit fly[10, 12]. However, a similar correlation between the gut metabolic switch and brain function modulation in mosquitoes is limited to the Aedes aegypti, where brain secreted Insulin-like-peptide 3 is reported to play a significant role in the regulation of blood meal digestion and egg development [13]. Only a few recent genetic studies have suggested the key role of few neuropeptides e.g. Neuropeptide-Y, Shortneuropeptide F, and Allatostatin-A, and their receptors in the suppression of host-seeking and paternity enforcement in Aedes aegypti mosquitoes[4, 14, 15]. Furthermore, it is becoming increasingly evident in vertebrates that an enteric nervous system (vagus nerve), also referred to as 'Second Brain'[16], not only mediates cross-talk between the gut and the brain but also establishes a bi-directional communication via gut-endosymbionts. This nexus of communication among the microbiota-gut-vagus-brain axis is crucial for maintaining 
metabolic homeostasis, mood, and perception[17-19]. Blood meal significantly modulates metabolic energy homeostasis in the mosquito gut, but how the gut's nutrient-sensing mechanism influences brain function remains unknown[20]. Although blood-meal-induced gut-flora proliferation has been well demonstrated in mosquitoes[21], their neuromodulatory functions remain elusive.

Using a comprehensive RNA-Seq analysis of mosquito brain, coupled with extensive transcriptional profiling of neuro-modulators, comparative metagenomics analysis, and LC/MS-based quantitative estimation of neurotransmitters, here we demonstrated that fast blood meal engorgement and gut-metabolic switching (i) boost the brain's energy-metabolism, which may likely influence organismal homeostasis, and (ii) favor the rapid establishment of a bidirectional microbiome-gut-brain axis communication, where the gut may also serve as a secondary brain in the blood-fed mosquitoes. Our data suggest that this gut-brain-axis communication is crucial for maintaining optimal physiological homeostasis during blood meal digestion and egg development in Anopheles culicifacies mosquitoes, the dominant malaria vector in rural India. A strategy of impairing this communication could reveal an out-of-thebox technique to disrupt mosquito host-seeking and blood-feeding behavior.

\section{Material and methods}

\section{Fig. $\mathrm{S1}$ represents a technical overview of the current investigation.}

Mosquito rearing and maintenance: A cyclic colony of An. culicifacies mosquito, sibling species A was reared and maintained at $28 \pm 2{ }^{\circ} \mathrm{C}$ temperature and relative humidity of $80 \%$ in the central insectary facility of the ICMR-National Institute of Malaria Research. For routine rearing, adult female mosquitoes were fed on the rabbit. All protocols for rearing and maintenance of the mosquito culture were approved by the ethical committee of the institute.

RNA isolation and transcriptome sequencing analysis: For RNA-Seq analysis, the brain tissues were dissected from 0-1-day old, $30 \mathrm{~min}$ post-blood-fed, and $30 \mathrm{~h}$ post-blood-fed cold anesthetized An. culicifacies mosquitoes by decapitation of the heads followed by application of gentle pressure over the head to pull out the brain tissue from the head cuticle and were collected in Trizol reagent. Then, total RNA was extracted from the collected brain tissues (approximately 30 mosquitoes were pooled to form one single sample), and a double-stranded cDNA library for each set of naïve, $30 \mathrm{~min}$, and $30 \mathrm{~h}$ post-blood-fed were prepared by a prior well-established PCR-based protocol [22]. For transcriptome sequencing, the Illumina MiSeq 2 X 150 paired-end library preparation protocol was followed. The bioinformatics data analysis pipeline is shown in Fig S1. Briefly, raw reads from each set were processed to remove the adaptors and low-quality bases $(<20)$. A de-novo clustering was used to build the final contigs/transcripts dataset using CLC Genomics Workbench (V6.2) (31) with default parameters (contig length $\geq 200$, Automatic word size: Yes, Perform Scaffolding: Yes, Mismatch cost: 2, Insertion cost: 3, Deletion cost: 3, length fraction: 0.5, Similarity fraction: 0.8). Finally, the assembled transcriptome was used for CDS prediction and annotation using transdecoder software and BLASTX at e-value $1 \mathrm{e}^{-6}$ respectively. For a comprehensive differential gene expression analysis, we used the same protocol as mentioned previously [1, 22]. Additionally, to identify the differentially expressed genes associated with certain biological and molecular processes, we performed gene-list enrichment analysis using the Kobas 3.0 web server. The unique appearance of certain pathways in different brain samples was screened depending on the p-value $(<0.5)$. 
PCR-based gene expression analysis: To establish the concept of the metabolic switch and inter-organ communication in mosquitoes, we targeted An. culicifacies brain, midgut, Malpighian tubule, and ovary tissues. The respective tissues were dissected and collected from both naïve sugar-fed and blood-fed mosquitoes originated from the same cohort at different time points. At first, the tissues were collected from 5-6-day old 25-30 naïve sugar-fed adult female mosquitoes. Next, adult female mosquitoes from the same cohort were offered bloodmeal by offering a live animal (rabbit), and the desired tissues were collected as per the technical design of the experiments. In general, the fully engorged females were separated and kept in a proper insectary condition and the tissues were collected at the selected time points of post-blood-meal (PBM) such as 5min PBM, 2h PBM, 8-10h PBM, 24-30h PBM, 48h PBM, and 72h PBM from 25-30 mosquitoes for tissue-specific detailed expression analysis of the respective genes. The different tissues were pooled accordingly in Trizol and total RNA was extracted, followed by cDNA preparation. Differential gene expression analysis was performed using the normal RT-PCR and agarose gel electrophoresis protocols. For relative gene expression analysis, SYBR Green qPCR master mix and Biorad CFX 96 Real-Time PCR machine was used. PCR cycle parameters involved an initial denaturation at $95^{\circ} \mathrm{C}$ for $5 \mathrm{~min}$, 40 cycles of $10 \mathrm{~s}$ at $95^{\circ} \mathrm{C}, 15 \mathrm{~s}$ at $52^{\circ} \mathrm{C}$, and $22 \mathrm{~s}$ at $72^{\circ} \mathrm{C}$. Fluorescence readings were taken at $72^{\circ} \mathrm{C}$ after each cycle. The final steps of PCR at $95^{\circ} \mathrm{C}$ for 15 secs followed by $55^{\circ} \mathrm{C}$ for 15 secs, and again $95^{\circ} \mathrm{C}$ for $15 \mathrm{secs}$ were completed before deriving a melting curve. Each experiment was performed in three independent biological replicates for a better evaluation of the relative expression. The actin or Rps7 gene was used as an internal control in all the experiments, and the relative quantification was analyzed by the $2^{-\Delta \Delta C t}$ method[23], which was further statistically analyzed by applying the student ' $t$ ' test and two-way ANOVA. The detailed list of primer sequences used in the study is mentioned in Table S1.

ROS determination assay of blood-fed mosquitoes brain: To unravel the origin of the oxidative stress response in the blood-fed brain, we performed reactive oxygen species (ROS) determination assay by incubating the brain tissue dissected from naïve and blood-fed mosquitoes with a $2 \mathrm{mM}$ solution of the oxidant-sensitive fluorophores, CM-H2DCFDA [5(and-6)-chloromethyl-29,79-dichloro-dichlorofluorescein diacetate, acetyl ester] (Sigma). After a 20-min incubation at room temperature in the dark, the brain tissues were washed thrice with PBS, and then transferred to a glass slide in a drop of PBS and checked the fluorescence intensity at wavelength $490 \mathrm{~nm}$ under a fluorescent microscope.

Antibiotic treatment of mosquitoes: To establish the concept of microbiome-gut-brain-axis communication, we disrupted the gut-commensal bacteria through antibiotic treatment. For the removal of gut bacteria, the pupae emerged in a washed and aseptic mosquito cage made up of muslin cloth. The antibiotic diet was provided to the newly emerged mosquitoes for 4-5days by mixing $10 \%$ sucrose solution with $10 \mu \mathrm{g}$ of penicillin-streptomycin/ml and $15 \mu \mathrm{g}$ gentamicin sulfate in it. To avoid any contamination, the antibiotic regimen was changed daily. After 4-5days of antibiotic treatment, blood-meal was provided to mosquitoes through the rabbit by maintaining proper sterile conditions such as (i) removed the extra hairs of rabbit pinnate/ears for easy access to blood meal, (ii) wipe the body of the rabbit with $70 \%$ ethanol, (iii) wipe the rabbit cage with alcohol.

Decapitation Experiment: To test mosquito's gut ability to function as a second brain, we offered a blood meal to 5-6 days old naïve sugar-fed mosquitoes, and decapitated 100 mosquitoes after one hour of blood-feeding. Next, the decapitated mosquitoes were securely kept back in the insectary for recovery. The head tissues were submerged in 1X PBS to avoid desiccation. As per the technical design, post decapitation, the percentage of mosquito's 
survival was recorded at different time points until we observed $100 \%$ mortality (mosquitoes that vibrate/move their legs or other body parts are considered as live and non-movable mosquitoes with visible shrinkage of the body parts at the respective time points are considered as dead). The brain and the gut tissues of surviving mosquitoes were dissected and collected at different time points for further gene expression analysis.

Sample processing and MS analysis for neurotransmitter quantification: For absolute quantification of neurotransmitters, mosquitoes were decapitated and brains pulled out from the head cuticle and quickly collected in an Eppendorf containing 50 $\mu$ l of $1 \%$ ascorbic acid and immediately freeze it. For each set, $\sim 60-65$ mosquito brains or guts were pooled in a single tube. All samples were stored at $-80^{\circ} \mathrm{C}$ until further use. Each sample was extracted with $3 \mathrm{X}$ volume of extraction solvent. Samples were vortexed and refrigerated for 10-15 minutes at $4^{\circ} \mathrm{C}$. Samples were then subjected to sonication in a bath-type ultra-sonicator in pulses (twice, for $1 \mathrm{~min}$ each). Samples were then centrifuged at $14500 \mathrm{rpm}$ for $5 \mathrm{mins}$ at $4^{\circ} \mathrm{C}$. The supernatants were separated and dried under a vacuum. Dried samples were spiked with internal standards (ISTDs) and derivatized, cleaned up, and prepared for LC-MS injections as per the protocol described earlier [24].

Briefly, Standards (STDs) were spiked in $200 \mu$ l of extraction solvent (acidic acetone $(0.1 \%$ FA) containing $0.5 \mathrm{mM}$ ascorbic acid) and dried under vacuum. ISTDs were spiked to dried STDs, followed by the addition of $80 \mu \mathrm{L}$ borate buffer $(200 \mathrm{mM}, \mathrm{pH} 8.8)$ containing $1 \mathrm{mM}$ ascorbic acid. To the above mixture $10 \mu \mathrm{l}$ of $0.1 \mathrm{~N} \mathrm{NaOH}$ was added, followed by the addition of AQC (from $1 \mathrm{mg} \mathrm{mL}-1$ stock). Samples were incubated at $55^{\circ} \mathrm{C}$ for $10 \mathrm{~min}$. The reaction was stopped by the addition of $500 \mu \mathrm{L}$ of acidic water $(0.1 \%$ FA). The derivatized standards were cleaned-up using the RP-SPE cartridges using the previously optimized protocol [25][24]: activation with methanol, equilibration with water $(0.1 \% \mathrm{FA})$, loading of samples, washing (twice) with water (0.1\% FA), and elution with acetonitrile: methanol (80:20) containing $2 \%$ FA. The eluate was dried under vacuum and reconstituted in $50 \mu \mathrm{L}$ of $0.5 \%$ acetonitrile. $10 \mu \mathrm{L}$ of reconstituted standards were injected for UHPLC-MS/SRM analysis.

Data were acquired on a TSQ Vantage (triple stage quadrupole) mass spectrometer (Thermo Fisher Scientific, San Jose, CA, USA) coupled with an Agilent 1290 Infinity series UHPLC system (Agilent Technologies India Pvt. Ltd.). The UHPLC system was equipped with a column oven (set at $40^{\circ} \mathrm{C}$ ) and a thermo-controller for maintaining the auto-sampler at $10{ }^{\circ} \mathrm{C}$. A C-18 column $(2.1 \times 100 \mathrm{~mm}, 1.8 \mu \mathrm{m}$, Agilent, Inc. $)$ was used to perform the separation. The mobile phase solvent A was $10 \mathrm{mM}$ ammonium acetate in water containing $0.1 \%$ formic acid, and solvent $\mathrm{B}$ was acetonitrile containing $0.1 \%$ formic acid. The gradient was optimized to get maximum separation (2\% B at $0 \mathrm{~min}, 2 \% \mathrm{~B}$ at $3 \mathrm{~min}, 20 \% \mathrm{~B}$ at $20 \mathrm{~min}, 35 \% \mathrm{~B}$ at $25 \mathrm{~min}, 80 \%$ $\mathrm{B}$ at $25-27 \mathrm{~min}, 2 \% \mathrm{~B}$ at $27-35 \mathrm{~min}$ ) at a flow rate of $200 \mu \mathrm{L} \mathrm{min}-1$. The operating conditions were as follows: ionization mode: positive; spray voltage: $3700 \mathrm{~V}$; capillary temperature: $270^{\circ} \mathrm{C}$; source temperature: $80^{\circ} \mathrm{C}$; sheath gas: 30 (arbitrary units); auxiliary gas: 10 (arbitrary units); collision gas: argon. Parent and product masses, S-lens voltages, and collision energies were used as per the previously optimized method [24, 25].

Metagenomics analysis \& microbiome profiling: For the metagenomics study, we collected gut from 3-4 days old sugar-fed adult female mosquitoes $(n=50)$. While for blood-fed mosquito gut samples, 3-4 days old adult female mosquitoes from the same cohort were provided bloodmeal by offering a live animal (rabbit), and midguts were collected after 24-30 hrs of bloodfeeding. Before dissection, the mosquitoes were surface sterilized with $70 \%$ ethanol for $1 \mathrm{~min}$ in the highly sterilized condition of the Laminar airflow, and dissected tissues were collected 
in $1 \mathrm{X}$ Saline Tris-EDTA (100 mM NaCl/10 mM Tris-HCl, pH 8.0/1 mM EDTA, pH 8.0) buffer. At least 50 whole guts either from naïve sugar-fed or blood-fed mosquitoes, originating from the same cohort were collected into the minimal volume (20ul) of sterile ice-cold 1X STE and whole DNA was extracted as described earlier[26]. The quality of extracted gDNA was checked by loading the $5 \mu \mathrm{l}$ aliquot on $1 \%$ agarose gel run at $110 \mathrm{~V}$ for $30 \mathrm{~min} .1 \mu \mathrm{l}$ of each sample was loaded in NanoDrop 8000 for determining the $A_{260 / 280}$ ratio. The DNA was quantified using the Qubit dsDNA BR Assay kit (Thermo Fisher Scientific Inc.). $1 \mu$ of each sample was used for determining concentration using Qubit ${ }^{\circledR} 2.0$ Fluorometer. For the preparation of amplicon libraries, V3-V4 hyper-variable region primers were used according to the library preparation protocol for the $16 \mathrm{~S}$ Metagenomic Sequencing. The library for the sequenced fragments was obtained as per the standard Illumina protocol. QIIME software was used for maximum-likelihood phylogeny inference[27], generating OTUs for taxonomic identification and diversity estimation was performed using Megan software[28] (Table S3, Fig. S2). To validate the metagenomics data, the abundancy of the selected bacterial species was profiled through Real-Time PCR as described earlier[26].

\section{Results:}

Hypothesis: Several independent studies highlighted the impact of age, sex, and circadian rhythm on the olfactory derived host-seeking behavioral properties of different mosquito species $^{26-28}$. However, a holistic understanding of how a coordinated action of the neuroolfactory system influences the host-seeking and blood-feeding behavioral properties remains unresolved $^{3}$. Since the neuro-system is a highly sensitive and versatile center of chemical information exchange, we hypothesize that a minor change in the innate physiological status may have a strong impact on the mosquito's everyday life. Importantly, after blood meal ingestion drastic changes in the innate physiological status and metabolic machinery i.e. "gut metabolic switch", may engage multiple organs, to manage the events of the gonotrophic cycle. Therefore, it is very much plausible to propose that fast engorgement of mosquito gut with blood meal may shift mosquitoes' brain functions from external communication to inter-organ management, such as (a) initiation of diuresis; b) finding a resting site for digestion of blood meal in the midgut; (c) distribution of amino acids, generated through the degradation of protein-rich blood meal; (d) active engagement of the fat body and ovary for egg maturation and life cycle maintenance (Fig. 1). We recently demonstrated that both mating and circadian have an important role in driving olfactory guided pre-blood-meal-associated behavioral properties even 'Without Host Exposure' in the aging adult female mosquito An. culicifacies[1, 29, 30]. Here, we aimed to decode and establish a possible molecular correlation between brain and gut-metabolic switch in An. culicifacies. First, to unravel the brain's molecular complexity in response to blood feeding, we followed a similar RNA-Seq strategy as planned for the olfactory system[1], as detailed in Fig.1. 


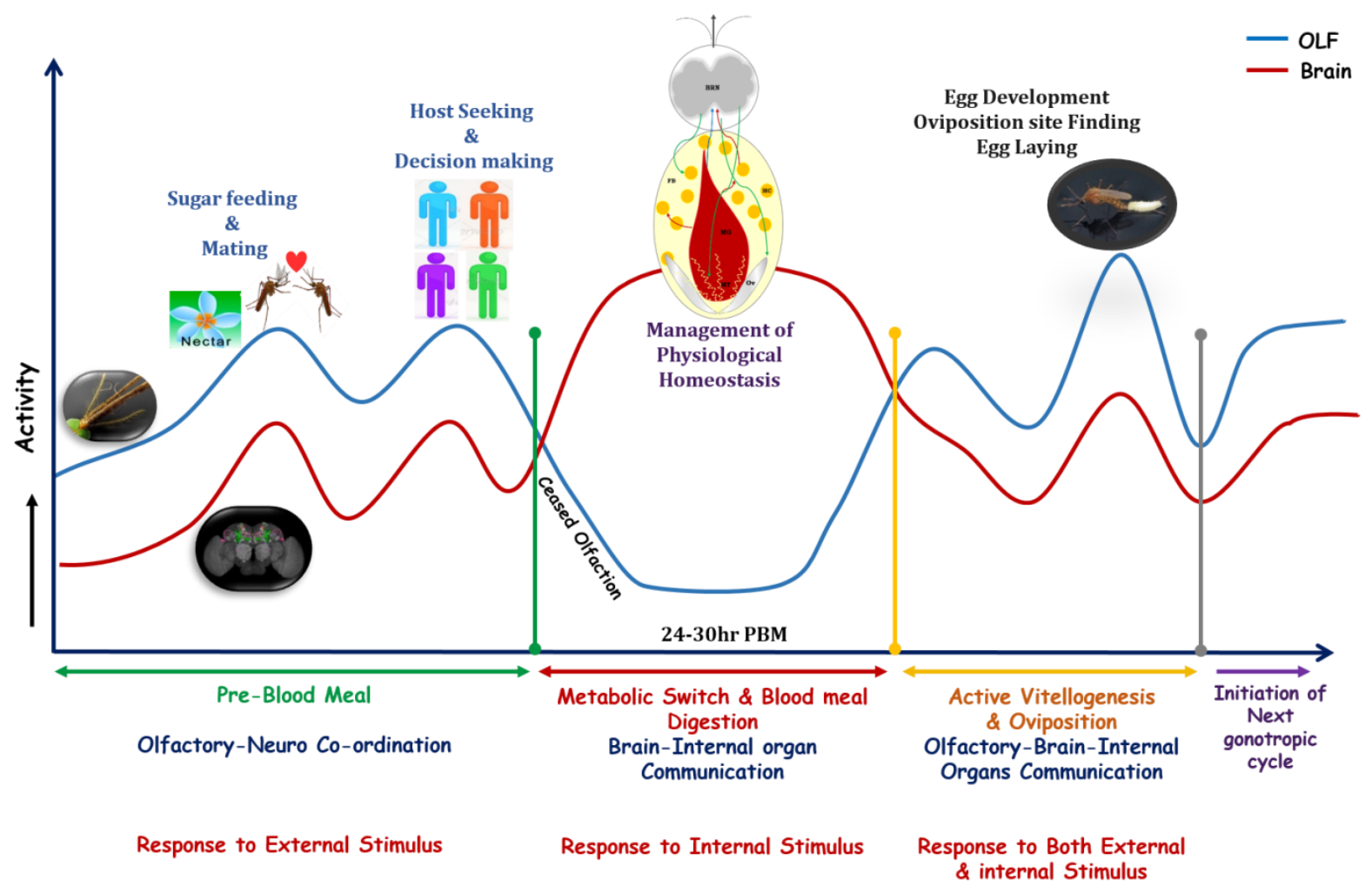

Fig. 1: A proposed working hypothesis to establish the correlation between the gut metabolic switch and brain functions in adult female mosquitoes. The behavior of any organism is a very complex event that needs tight coordination between the sensory and neuronal systems. After emergence from pupae, the dynamic changes in the neuro-olfactory system coordinate and regulate different behavioral activities such as mating, sugar feeding, and vertebrate host-seeking, etc. These pre-blood meal-associated behaviors are guided by external stimuli, followed by neuronal decision making. Once the female mosquitoes take a blood meal, their olfactory responses are temporarily arrested to minimize brain and environmental (external) communication. But blood-feeding causes a global change in physiological homeostasis and drives multiple tissues (midgut, Malpighian tubule, ovary, and fat body) engagement to manage the systemic equilibrium. Here, we hypothesize that an 'internal stimulus' of gut-metabolic-switch may modulate brain functions to ensure optimal inter-organ communication at least for the first $30 \mathrm{~h}$ until blood meal digestion is completed in the gut. However, after 30-40h of blood-feeding reactivation of the olfactory system, restores olfactory-neuro coordination to perform the next level of behavioral activities, such as oviposition and initiation of the second gonotrophic cycle. Blue and red lines indicate the possible functional patterns of the olfactory system (OLF) and the brain, respectively.

Blood meal ingestion boosts the brain's energy metabolism: A comparative analysis of naïve sugar-fed, 30min, and 30hpostblood-fed mosquito's brain RNA-Seq data showed a gradual suppression of brain-specific transcript abundance (Fig. 2a). Surprisingly, we also observed an exceptional enrichment of oxidation-reduction process associated transcripts in response to blood-feeding (Fig. 2b) (Table S2a, S2b), though, we failed to detect any signal of oxidative stress in a $2 \mathrm{mM}$ solution of the oxidant-sensitive fluorophores, CM-H2DCFDA [5(and-6)-chloromethyl-29,79-dichloro-dihydrofluorescein diacetate, acetyl ester] (data not are shown). While an in-depth analysis of oxidation-reduction category transcripts showed enrichment of several mitochondrial activity proteins such as 2-oxoglutarate dehydrogenase, $\mathrm{NADH}$ dehydrogenase, glutathione peroxidase, etc. A comparative metabolic pathway prediction analysis further confirmed the exclusive induction of several unique pathways linked 
to (a) energy metabolism, (b) neurotransmitter synthesis, and (c) neurite outgrowth and synaptic transmission (Fig. 2c). Together these data indicated that blood meal associated gut metabolic switch may trigger a "hyper energy" state and neuro-modulatory factors in the mosquito brain.

To verify the above presumption, we profiled and compared the expression pattern of the PGC1 gene (Peroxisome proliferator-activated receptor gamma coactivator 1-alpha), an important transcriptional co-activator that regulates genes involved in energy metabolism[31-33]. A persistent elevation of PGC-1 (P $\leq 0.009$ at $8 \mathrm{~h}$ PBM, $\mathrm{P} \leq 0.007$ at $30 \mathrm{~h} \mathrm{PBM})$, and a parallel enrichment of glycolysis and TCA cycle gene pyruvate kinase $(\mathrm{P} \leq 0.0176)$ and oxoglutarate dehydrogenase $(\mathrm{P} \leq 0.0019)$ respectively, indicated an enhanced mitochondrial activity in the brain of blood-fed mosquitoes (Fig. 2d, e). Next, we tested whether the amino acids generated through blood meal digestion or trehalose, a non-reducing disaccharide, acts as raw material for the brain's energy metabolism. Although trehalose serves as a primary energy source in the insects' brain $[34,35]$, we observed a sequential increment in the amino acid $(\mathrm{P} \leq 0.0515)$ as well as trehalose $(\mathrm{P} \leq 0.0071)$ transporter genes in the blood-fed brain (Fig. 2f). Together, these data indicate that both amino acids and trehalose may synergistically communicate the nutritional signal to the brain for active management of multi-organ communication[13, 36]. 


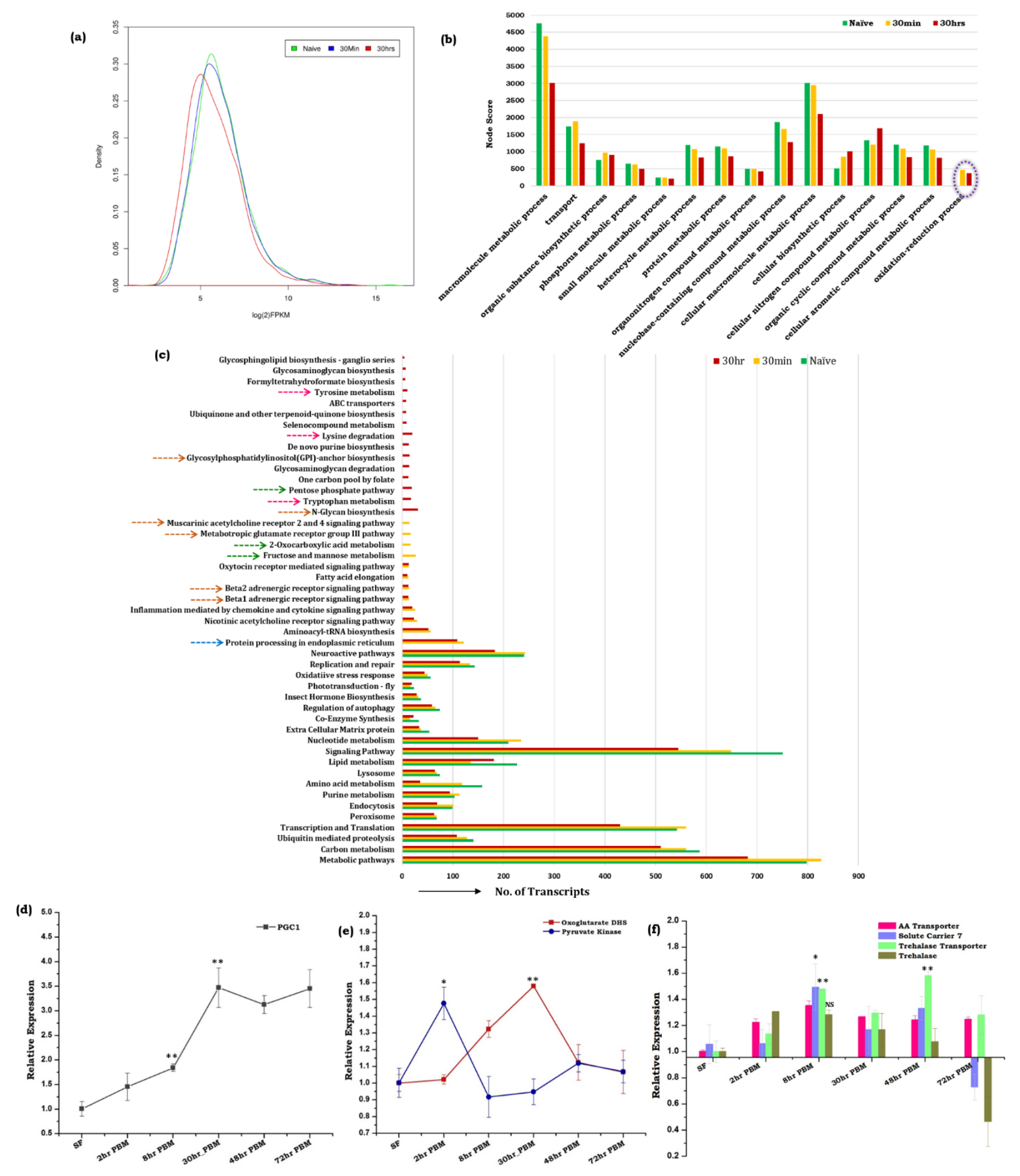

Fig. 2: Blood meal causes notable changes in the molecular architecture of the brain tissue. (a) Comparison of the read density map of the naïve, 30min, and 30h post blood meal (PBM) transcriptomic data of brain tissue ( $\mathrm{n}=25)$; (b) Functional annotation and molecular cataloging of brain transcriptome (Biological Process/Level4/Node score). Purple circle highlighted the unique category of genes that appeared in the brain tissue after blood meal intake; (c) KOBAS 3.0 software mediated gene list enrichment and comparative pathway analysis of naïve and blood-fed brain tissues. Green arrow links to energy metabolic pathways, the pink arrow links to neurotransmitter synthesis pathway, and brown arrow indicate neurite out-growth and synaptic transmission; (d) Relative expression profiling of PGC1 gene in the brain of naïve and blood-fed $\operatorname{mosquitoes}(n=25, N=3)$; (e) Transcriptional profiling of 
transcripts related to energy metabolism in the brain tissue of naïve and blood-fed mosquitoes at different time points; (f) Comparative transcriptional response of amino acid transporters and trehalose transporter along with trehalase enzyme in the brain tissue after the metabolic switch $(n=25, N=3)$. Statistically significant variation in the expression of the respective genes was tested by the $t$-test and compared with the sugar-fed control brain. $(\mathrm{n}=$ number of mosquitoes from, which the respective tissue was dissected and pooled for each independent experiment; $\mathrm{N}=$ number of biological replicates)

Spatial and temporal modulations of neuro-signaling regulate metabolic switchassociated physiological activities: In naive sugar-fed mosquitoes, olfactory guided neurosignaling and the brain's energy consumption is optimal to drive external stimuli associated with routine behavioral events like flight, mating, and host-seeking. Recently, we have demonstrated that prior host-exposure, sex, and circadian have a significant impact on the olfactory responses in the aging adult-female mosquito An. culicifacies [1, 29, 30]' Likewise, to test and evaluate the possible correlation of age with neuro-regulation, we monitored the expression profile of at least 14 neuro-modulatory genes in aging naïve adult female mosquito's brain (Fig. S3). A limited modulation of expression suggested that host exposure may have an important role in cognitive learning and blood-feeding behavioral adaptation in mosquitoes, though further studies are needed to clarify and establish the correlation. However, surprisingly, after blood feeding an increase in the brain's energy consumption, prompted us to test the functional correlation of the brain with gut metabolic switch activities. Here, we hypothesize that blood meal uptake may temporarily pause the external communication, and increased energy state possibly may favor the shifting of the brain's engagement for the maintenance of organismal homeostasis. Thus, we identified and shortlisted transcripts encoding proteins, likely involved in the key events of the synaptic signal transmission process, i.e., crucial for the brain's functioning. Thereafter, we evaluated the blood-meal-associated transcriptional response of selected transcripts regulating either receptor-mediated neuronal or cellular signaling processes during synaptic transmission.

Surprisingly, we observed a limited change in the expression of neurotransmitters and biogenic amine receptor genes such as serotonin receptor, dopamine receptor, octopamine receptor, and GABA receptor, etc. in response to blood-meal (Fig. 3a). While, on the contrary, cellular signal transduction proteins such as cGMP protein kinase, phospholipase C, GABA gated chloride channel, and serine-threonine protein kinase, exhibited a significant modulation in response to metabolic switch (Fig. 3b). Together, these findings support the idea that a rapid blood meal ingestion may drive brain engagement to manage metabolic switch-associated activities and distant organs' function.
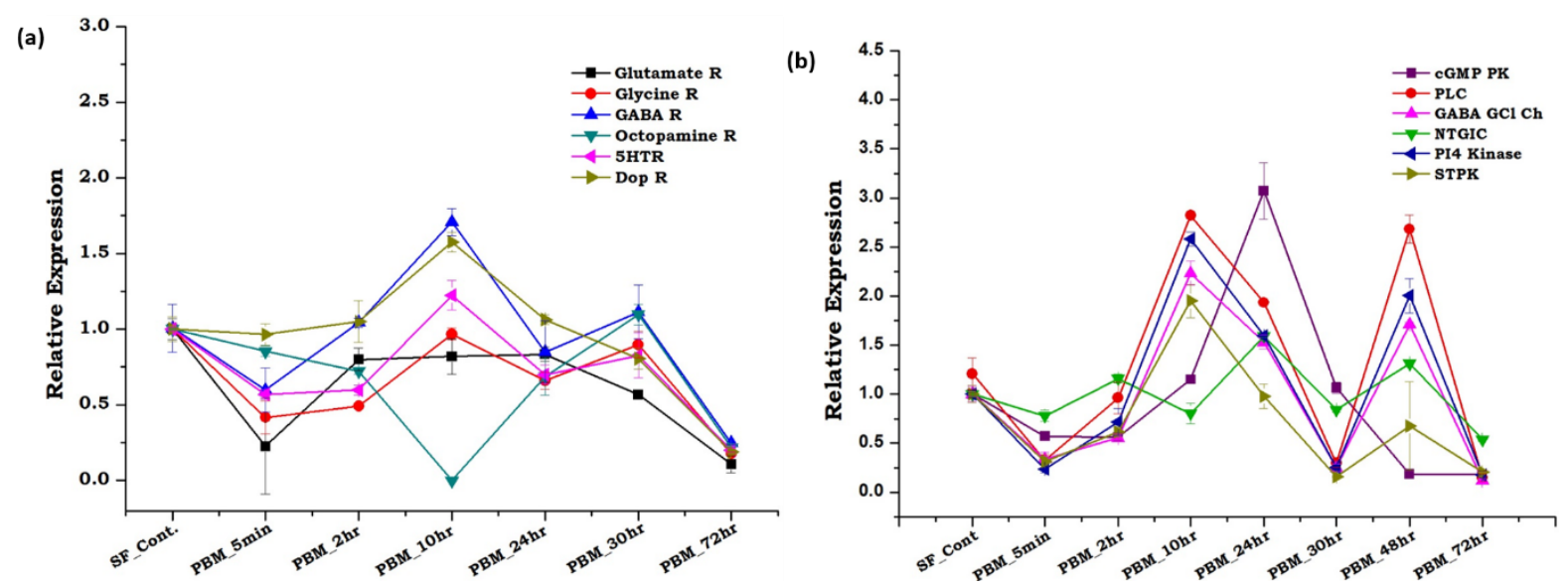
Fig. 3: Metabolic switch influences neuro-signaling modulation. (a) Transcriptional response of neurotransmitter receptor genes as per the designed blood meal time-series experiment. Glutamate R: Glutamate Receptor; Glycine R: Glycine Receptor; GABA R: Gamma-Aminobutyric Acid Receptor; Octopamine R: Octopamine Receptor; 5HTR: Serotonin Receptor; Dop R: Dopamine Receptor. Statistical analysis using two-way ANOVA has implied at 0.05 level the expression pattern of the respective genes was not statistically significant at $\mathrm{p} \leq 0.2$ at different time points after blood feeding ( $n=25, N=4)$; (b) Relative expression profiling of the genes involved in signal transduction molecules according to the detailed blood meal time-series experiment. cGMP PK: Cyclic GMP Protein Kinase; PLC: Phospholipase C; GABA GClCh: GABA Gated Chloride Channel; NTGIC: Neurotransmitter Gated Ion Channel; PI4 Kinase: Phosphatidyl-inositol-4-Kinase; STPK: Serine Threonine Protein Kinase. Statistical analysis using two-way ANOVA stated that the expression change of the respective genes is statistically significant $\mathrm{p} \leq 0.005(n=25, N=4)$. $(\mathrm{n}=$ number of mosquitoes from which the respective tissue was dissected and pooled for each independent experiment; $\mathrm{N}=$ number of biological replicates)

Innate physiological status differentially modulates tissue-specific neuromodulators/receptors transcripts expression: To further validate and correlate braininter-organ communication, we monitored the temporal and spatial expression of at least 21 key genes (Table 1) having the blood-meal-associated function in their targeted tissue such as midgut (MG), ovary (Ov), and Malpighian tubules (MT). Notably, we observed a significant upregulation of ILP3 $(\mathrm{p}<0.0002)$ and also time-dependent modulation of other neuropeptides (Neuropeptide Y, Leukokinin) and neuro-hormones (OEH, DH44, and ARMAA) in the bloodfed mosquitoes brain (Fig. 4a, b, c). We interpreted that a gradual induction of ILP3 synthesis and $\mathrm{OEH}$ secretion from the brain's neurosecretory cells may activate the ovaries for the synthesis of ecdysteroids to initiate the vitellogenesis process [37-39]. A transient increase in NRY immediately after blood-feeding may be due to gut distension, but a significant increase $(\mathrm{P}<0.005)$ after $24 \mathrm{~h}$ and $72 \mathrm{~h}$ may cause suppression of host-seeking, a mechanism recently reported in Aedes aegypti $[4,40]$.

Next, we asked how the dynamic changes of the neuromodulators in the blood-fed brain influence distant organs responses, such as diuresis regulation by the Malpighian tubule, blood digestion process in the midgut, and oocyte maturation in the ovary. Transcriptional profiling of selected neuropeptide, neurotransmitter receptor transcripts (Table 1) indicated that blood meal triggers an immediate and prolonged $(\sim 48 \mathrm{~h} \mathrm{PBF})$ impact on the expression of the gutneuro transcript (Fig. 4d). Parallel observation of an early induction (2h PBF) of serine threonine-protein kinase (MAPK activated protein kinase) and late expression of Akt kinase (48h PBF) in the ovary suggested a controlled regulation of the nutritional signaling pathway favors the vitellogenesis process (Fig. 4e) [9, 41]. Likewise, observation of a unique pattern of diuretic hormone (8h PBF) and potassium dependent sodium-calcium exchanger gene (24h $\mathrm{PBF})$ expression in the Malpighian tubule suggested an active diuresis process until $24 \mathrm{~h}$ post blood meal (Fig. 4f) [42].

Table 1: Details of the selected transcripts used to understand inter-organ communication during metabolic switch events

\begin{tabular}{|c|l|l|l|l|l|}
\hline $\begin{array}{c}\text { Sl. } \\
\text { No. }\end{array}$ & \multicolumn{1}{|c|}{ Gene Name } & $\begin{array}{l}\text { Synthesized } \\
\text { From }\end{array}$ & $\begin{array}{c}\text { Target } \\
\text { Tissue }\end{array}$ & Possible Function & $\begin{array}{c}\text { Target } \\
\text { Tissue for } \\
\text { Expression } \\
\text { study }\end{array}$ \\
\hline 1. & ILP1 & $\begin{array}{l}\text { MNSC of } \\
\text { brain }\end{array}$ & Ovary & $\begin{array}{l}\text { Halt ovarian maturation } \\
{[43]}\end{array}$ & Brain, midgut \\
\hline
\end{tabular}




\begin{tabular}{|c|c|c|c|c|c|}
\hline 2. & ILP3 & $\begin{array}{l}\text { MNSC of } \\
\text { brain }\end{array}$ & $\begin{array}{l}\text { Midgut, } \\
\text { Ovary, Fat } \\
\text { Body, } \\
\text { Hemocyte }\end{array}$ & $\begin{array}{l}\text { Nutrient storage by } \mathrm{FB} \text {, } \\
\text { regulation of digestive } \\
\text { enzymes by MG, } \\
\text { Ecdysteroid production } \\
\text { from ovaries, the } \\
\text { immune response by } \\
\mathrm{HC}[9,38,44]\end{array}$ & Brain, midgut \\
\hline 3. & Leucokinin & $\begin{array}{l}\text { Abdominal } \\
\text { ganglia }\end{array}$ & $\begin{array}{l}\text { Gut, } \\
\text { Malpighian } \\
\text { tubule }\end{array}$ & $\begin{array}{l}\text { Regulation of fluid } \\
\text { secretion, ionic balance } \\
{[45]}\end{array}$ & Brain \\
\hline 4. & $\begin{array}{l}\text { PTTH } \\
\text { Prothoracicotropic } \\
\text { Hormone }\end{array}$ & Brain & Not Known & $\begin{array}{l}\text { Diapause and blood- } \\
\text { feeding [46] }\end{array}$ & Brain \\
\hline 5. & $\begin{array}{ll}\text { Neuropeptide } & Y \\
\text { Receptor -NRY } & \end{array}$ & NSC of brain & Brain & $\begin{array}{l}\text { Host-seeking inhibition } \\
{[4,40]}\end{array}$ & Brain \\
\hline 6. & $\begin{array}{l}\text { Leucokinin } \\
\text { Receptor }\end{array}$ & $\begin{array}{l}\text { Multiple } \\
\text { tissues }\end{array}$ & $\begin{array}{l}\text { Multiple } \\
\text { tissues }\end{array}$ & $\begin{array}{l}\text { Regulation of fluid } \\
\text { secretion, ionic balance } \\
{[47]}\end{array}$ & Brain, midgut \\
\hline 7. & $\begin{array}{l}\text { Diuretic hormone } \\
44 \text { (DH44) }\end{array}$ & $\begin{array}{l}\text { Gut } \\
\text { endocrine } \\
\text { cells }\end{array}$ & $\begin{array}{l}\text { Malpighian } \\
\text { tubule }\end{array}$ & $\begin{array}{l}\text { Regulation of diuresis } \\
\text { [42] }\end{array}$ & Brain, midgut \\
\hline 8. & $\begin{array}{l}\text { OEH - Ovary } \\
\text { Ecdysteroidogenic } \\
\text { Hormone }\end{array}$ & $\begin{array}{l}\text { MNSC and } \\
\text { ventricular } \\
\text { ganglia of the } \\
\text { brain }\end{array}$ & Ovary & $\begin{array}{l}\text { Induces ecdysone } \\
\text { production from the } \\
\text { ovary after blood } \\
\text { feeding [47] }\end{array}$ & Brain \\
\hline 9. & $\begin{array}{l}\text { ARMAA } \\
\text { Aromatic-L- } \\
\text { amino-acid } \\
\text { decarboxylase }\end{array}$ & $\begin{array}{l}\text { Multiple } \\
\text { tissues }\end{array}$ & $\begin{array}{l}\text { Multiple } \\
\text { tissues }\end{array}$ & $\begin{array}{l}\text { Synthesis of serotonin } \\
\text { neurotransmitter and } \\
\text { regulation of multiple } \\
\text { physiological processes }\end{array}$ & Brain \\
\hline 10. & DH44R1 & $\begin{array}{l}\text { Malpighian } \\
\text { tubule }\end{array}$ & $\begin{array}{l}\text { Malpighian } \\
\text { tubule }\end{array}$ & $\begin{array}{l}\text { Regulation of Diuresis } \\
{[42,47]}\end{array}$ & $\begin{array}{l}\text { Midgut and } \\
\text { Malpighian } \\
\text { tubule }\end{array}$ \\
\hline 11. & $\begin{array}{l}\text { CCHamide } \\
\text { Receptor } 2\end{array}$ & $\begin{array}{l}\text { CCHamide2 } \\
\text { synthesized } \\
\text { from gut } \\
\text { endocrine } \\
\text { cells }\end{array}$ & $\begin{array}{l}\text { Multiple } \\
\text { tissues }\end{array}$ & $\begin{array}{l}\text { Nutrient dependent } \\
\text { regulation of ILPs from } \\
\text { brain [47] }\end{array}$ & Midgut \\
\hline 12. & $\begin{array}{l}\text { 5HTR - Serotonin } \\
\text { Receptor }\end{array}$ & $\begin{array}{l}\text { Multiple } \\
\text { tissues }\end{array}$ & $\begin{array}{l}\text { Multiple } \\
\text { tissues }\end{array}$ & $\begin{array}{l}\text { Multiple behavioral and } \\
\text { physiological processes } \\
{[48,49]}\end{array}$ & Midgut \\
\hline 13. & $\begin{array}{lll}\text { Glutamate } & \mathrm{R} \quad- \\
\text { Glutamate } & & \\
\text { Receptor } & & \end{array}$ & $\begin{array}{l}\text { Multiple } \\
\text { tissues }\end{array}$ & $\begin{array}{l}\text { Multiple } \\
\text { tissues }\end{array}$ & 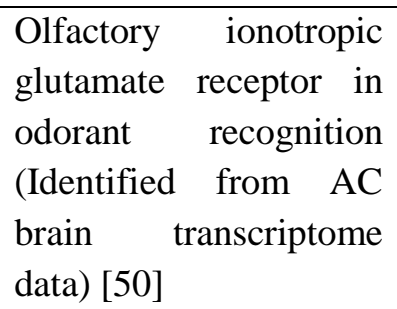 & Midgut \\
\hline
\end{tabular}




\begin{tabular}{|c|c|c|c|c|c|}
\hline 14. & $\begin{array}{l}\text { Glycine } \mathrm{R} \\
\text { Glycine Receptor }\end{array}$ & $\begin{array}{l}\text { Multiple } \\
\text { tissues }\end{array}$ & $\begin{array}{l}\text { Multiple } \\
\text { tissues }\end{array}$ & $\begin{array}{l}\text { Inhibit } \\
\text { neurotransmission } \\
\text { (Identified from AC } \\
\text { brain transcriptome } \\
\text { data) [51] }\end{array}$ & Midgut \\
\hline 15. & $\begin{array}{l}\text { Akt Kinase } \\
\text { Protein kinase B }\end{array}$ & $\begin{array}{l}\text { Fat body, } \\
\text { ovary }\end{array}$ & Ovary & $\begin{array}{l}\text { Activation of } \\
\text { pathway [9] }\end{array}$ & Ovary \\
\hline 16. & $\begin{array}{l}\text { CYP31A41-20E } \\
\text { hydroxylase }(20 \mathrm{E} \\
\text { synthesizing } \\
\text { enzyme) }\end{array}$ & Ovary & $\begin{array}{l}\text { Fat body } \\
\text { and ovary }\end{array}$ & $\begin{array}{l}\text { Ovary and oocyte } \\
\text { development [52] }\end{array}$ & Ovary \\
\hline 17. & $\begin{array}{l}\text { STPK - Serine } \\
\text { threonine-protein } \\
\text { kinase }\end{array}$ & Multiple & Multiple & $\begin{array}{l}\text { Multiple physiological } \\
\text { processes [41] }\end{array}$ & Ovary \\
\hline 18. & PI4-Kinase & Multiple & Multiple & $\begin{array}{l}\text { Multiple physiological } \\
\text { processes (Identified } \\
\text { from AC brain } \\
\text { transcriptome data) }\end{array}$ & Ovary \\
\hline 19. & $\begin{array}{l}\text { Calcitonin } \\
\text { Receptor }\end{array}$ & $\begin{array}{l}\text { Malphigian } \\
\text { tubule }\end{array}$ & $\begin{array}{l}\text { Malphigian } \\
\text { tubule }\end{array}$ & $\begin{array}{l}\text { Regulation of diuresis } \\
{[42,53]}\end{array}$ & $\begin{array}{l}\text { Malphigian } \\
\text { tubule }\end{array}$ \\
\hline 20. & $\begin{array}{l}\text { KDNaCa } \\
\text { Exchanger }\end{array}$ & $\begin{array}{l}\text { Malpighian } \\
\text { tubule }\end{array}$ & $\begin{array}{l}\text { Malpighian } \\
\text { tubule }\end{array}$ & $\begin{array}{l}\text { Regulate fluid secretion } \\
\text { and diuresis [42] }\end{array}$ & $\begin{array}{l}\text { Malpighian } \\
\text { tubule }\end{array}$ \\
\hline 21. & V-Type ATPase & $\begin{array}{l}\text { Malpighian } \\
\text { tubule }\end{array}$ & $\begin{array}{l}\text { Malpighian } \\
\text { tubule }\end{array}$ & $\begin{array}{l}\text { Regulate membrane } \\
\text { potential and diuresis } \\
{[42]}\end{array}$ & $\begin{array}{l}\text { Malpighian } \\
\text { tubule }\end{array}$ \\
\hline
\end{tabular}
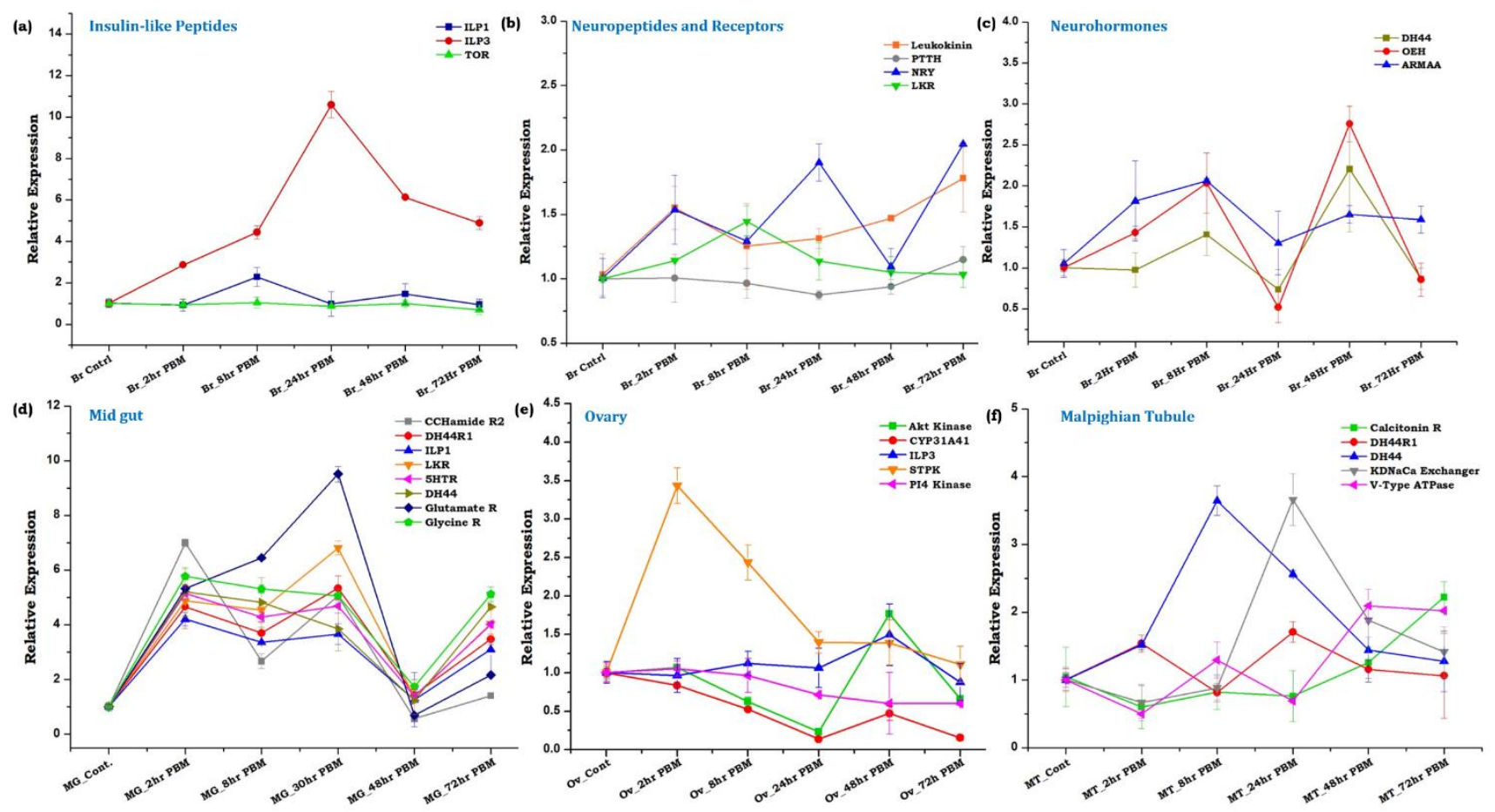

Fig. 4: Metabolic switch modulates tissue-specific neuro-modulator transcripts expression. (a-c) Transcriptional expression profiling of Insulin-like-peptides, neuropeptides, neurohormones, and 
receptor genes in the brain tissue during the metabolic switch. Statistical analysis using two-way ANOVA and Tukey's test implied that the expression change of the respective genes is statistically significant for insulin-like-peptides $\mathrm{p} \leq 0.007$; neuropeptides and receptors $\mathrm{p} \leq 0.009$, but for neurohormones, it was non-significant $\mathrm{p} \leq 0.2(n=25, N=4)$; (d) Relative expression profiling of a subset of neuromodulator genes in the midgut of naïve and blood-fed mosquitoes at the same time point described above. Statistical analysis using two-way ANOVA implied that the expression change of the respective genes is statistically significant $\mathrm{p} \leq 0.005(n=12, N=4)$; (e) Transcriptional profiling of genes involved in signal transduction during vitellogenesis in the ovary. Statistical analysis using twoway ANOVA and Tukey's test indicated that the expression change of the respective genes was statistically significant at $\mathrm{p} \leq 0.002(n=12, N=4)$; (f) Relative gene expression analysis of diuresisrelated genes in the Malpighian tubule of naïve and blood-fed mosquitoes. Statistical analysis using two-way ANOVA and Tukey's test indicates that the expression change of the respective genes is nonsignificant at $\mathrm{p} \leq 0.4(n=25, N=4)$. ( $\mathrm{n}=$ number of mosquitoes from which the respective tissue was dissected and pooled for each independent experiment; $\mathrm{N}=$ number of biological replicates)

Gut, the 'second brain' communicates the nutritional status through neurotransmitter synthesis: In vertebrates and also in the fruit flies, it is well evident that effective communication between the gut and brain has a paramount effect in shaping optimal health[16, 18], but a very limited knowledge exists in the mosquitoes[13]. Prolonged modulation of the neuromodulators expression in the blood-fed mosquitoes' gut invigorates us to presume the existence of bi-directional gut-brain axis communication. An enriched expression pattern of neurotransmitter receptor genes, even after decapitation, reflected that the gut may also perform neuro-modulatory actions independently (Fig. S3). To further establish a proof-of-concept, we followed LC/MS-based absolute quantification of different neurotransmitters (NT) and compared their levels in the brain as well as in the gut of naïve and blood-fed mosquitoes.

Our data revealed that in naïve sugar-fed mosquitoes, although the brain serves as the primary source of NT synthesis, the midgut also synthesizes a substantial amount of NTs (Fig. 5a). However, blood-feeding causes a drastic shift in the NTs level in the midgut than in the brain (Fig. b, c). Notably, we observed an unpredictable increase in most NTs except glutamic acid, tyrosine, and tyramine in the gut (Fig. 5c). Whereas, the brain tissue showed a notable decrease in the majority of the NTs synthesis, except for histamine, tyrosine, and tryptophan (Fig. 5b). We also observed that tyrosine amino acid was exclusively induced in the brain after bloodfeeding, but remained below the threshold level in the gut (Fig. 5 b, c). Although our data support previous studies that in addition to the brain, the gut also serves as a major source of multiple neurotransmitters in vertebrates and fruit fly[16, 54], the mechanism of nutritiondependent NTs modulation remains unclear. Especially, in mosquitoes our understanding of the complex nature of blood meal digestion and gut-brain axis communication is obscure. Thus, our unusual observation of a thousand-fold increase in the levels of histidine, serine, aspartic acid, and tryptophan in the blood-fed mosquito's gut emanated few key questions: 1) whether increased levels of amino acids in the gut during blood meal digestion may act as an NT? 2) Do blood-meal-induced proliferation of the gut microbiota has any effect on NT dynamics? 3) Do the gut endosymbionts of mosquitoes have any impact on gut-brain axis communication? (Fig. 5d). 


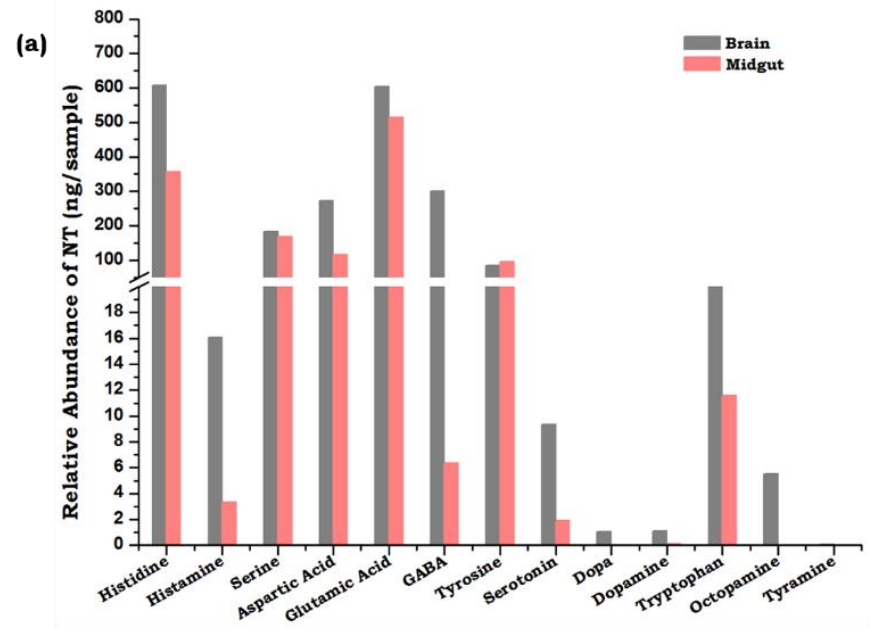

(b)

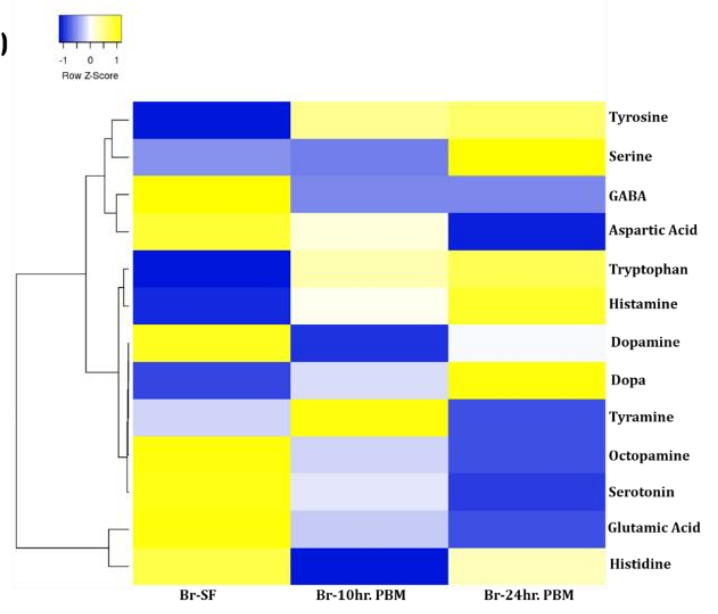

(d)

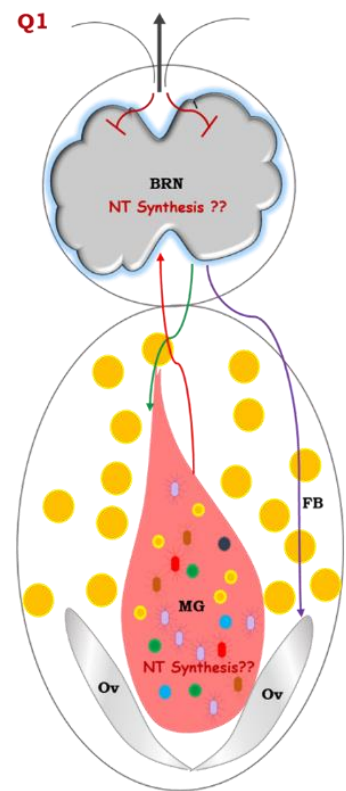

(c)

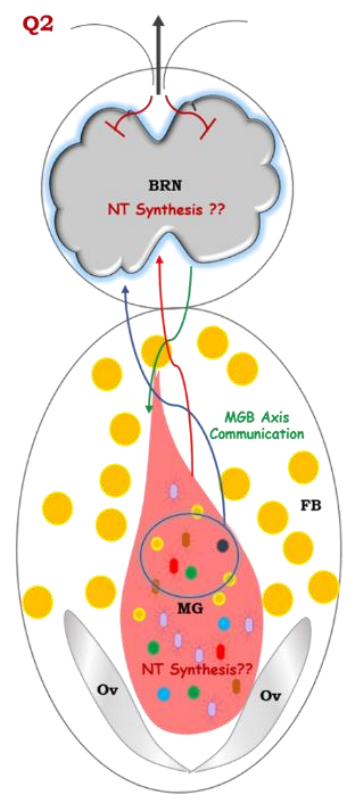

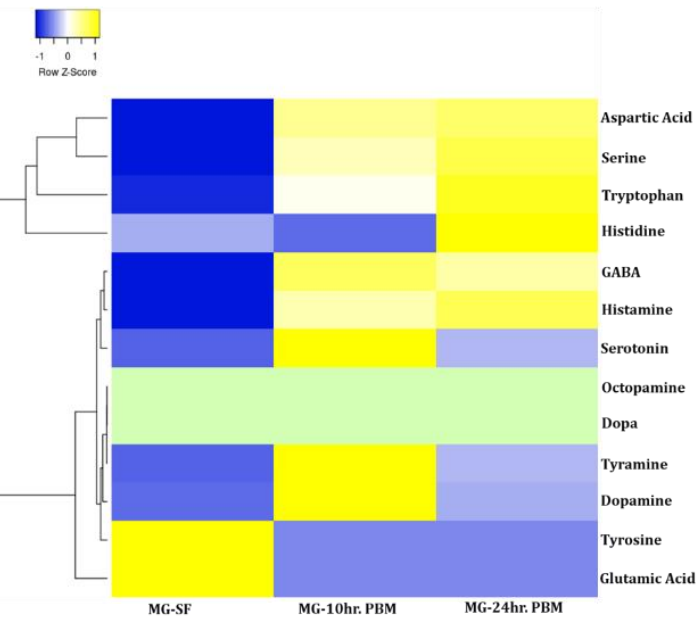
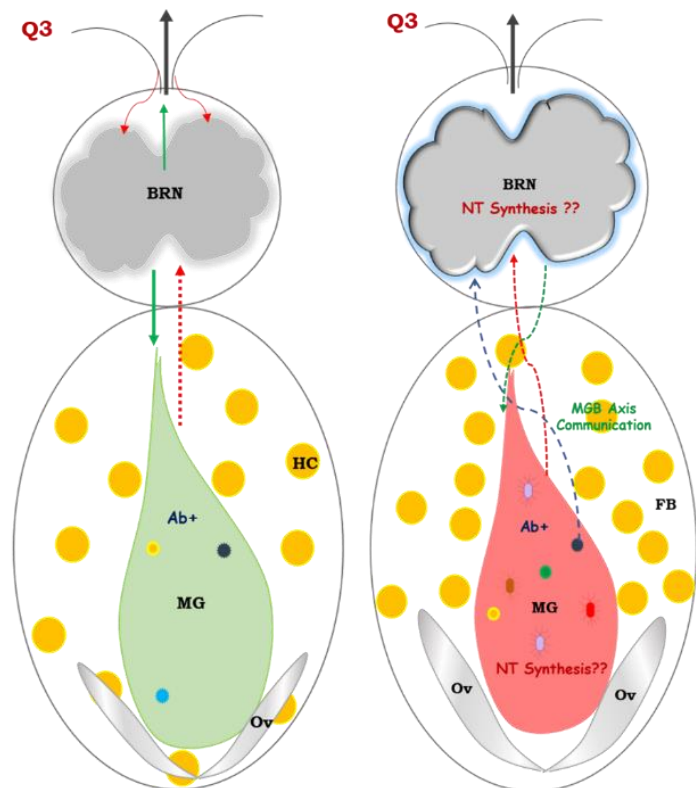

Fig. 5: Gut-Brain-Axis (GBA) communication and neurotransmitter (NT) estimation in mosquito An. culicifacies. (a) Comparative analysis of NT abundance in the naïve mosquitoes' brain and midgut; (b) Heatmap showing the alteration of neurotransmitters level in mosquito brain tissue. NT levels were measured by LC-MS from the brains of naïve (sugar-fed) and blood-fed females (10 and $24 \mathrm{~h}$ PBM) (n $=65, \mathrm{~N}=2$ ). Statistically significant differences in the amount of metabolites were tested by $\mathrm{p}$-values $(\mathrm{p} \leq 0.005)$ that are deduced by two-way ANOVA and Tukey's test; (c) Heatmap of neurotransmitters 
levels of mosquito gut tissue that vary during the metabolic switch. NT levels were measured by LCMS from the gut of naïve (sugar-fed) and blood-fed females (10 and $24 \mathrm{~h} \mathrm{PBM)}(\mathrm{n}=50, \mathrm{~N}=2)$. Statistically significant differences in the amount of metabolites were tested by $p$-values $(p \leq 0.005)$ that are deduced by two-way ANOVA and Tukey's test. ( $\mathrm{n}=$ number of mosquitoes from which the respective tissue was dissected and pooled for each independent experiment; $\mathrm{N}=$ number of biological replicates); (d) Pictorial presentation demonstrating GBA communication in response to gut-metabolic switch in mosquitoes. Q1: Blood-feeding pauses external stimulus-guided neuro-olfactory responses, but may shift brain engagement through the vagus pathway (red arrow) to regulate actions in the distant organs such as the midgut (green arrow) and ovary (purple arrow). Here, we questioned whether increased levels of amino acids in the gut during blood meal digestion may act like an NT. Q2: Do blood-meal-induced gut flora proliferation (different colored shapes indicate diverse microbial flora) influence GBA communication in mosquitoes. Q3: Whether gut-bacterial removal by antibiotic treatment confers the establishment of microbiome-gut-brain axis (MGB) communication. BRN: Brain, MG: midgut, FB: Fat body, Ov: Ovary, Ab+: Antibiotic positive/treated.

Symbiotic gut flora influences gut-brain axis communication: The mechanism of gut-brain axis communication in vertebrates primarily involves neuronal stimulation through the vagus nerve, endosymbionts mediated regulation of the gut endocrine system, and other biochemical pathways $[18,19,55]$. Previous literature suggests that mosquito gut endosymbionts regulate many biological functions such as mosquito immunity, blood meal digestion, and ecological adaptation $[49,56]$. Ingestion of protein-rich blood meal favors the rapid enrichment of gut microbiota[21], but whether it also affects the nexus of communication between the gut and brain remains elusive.

Therefore, to uncover the gut microbiome complexity and establish their possible relations with neurotransmitter abundancy, we evaluated the nature and diversity of gut microbiome population dynamics alteration in response to blood-feeding. A comparative metagenomic analysis unraveled that the naïve sugar-fed mosquito harbors $90 \%$ of the Enterobacteriaceae family of gram-negative gamma-proteobacteria such as Enterobacter cloacae complex sp., Chonobacter sp., Escherichia coli; $6 \%$ Psedomonodales family of gram-negative gammaproteobacteria such as (a) Acinetobacter sp. members e.g. Acinetobacter guillouiae, Acinetobacter iwoffii, (b) Pseudomonas aeruginosa sp. group e.g. Pseudomonas alcaligenes, $P$. nitroreducens, $P$. veronii, $P$. stutzeri and $P$. viridiflava; and other bacterial family member of Bacteroidetes e.g. Flavobacteriacae - Chryseobacterium sp., Elizabethkingia meningospetica; beta-proteobacteria-Alcaligenaceae- Alcaligenes faecalis (Fig. 6/ Fig. S4a, b, c). However, surprisingly blood feeding not only supresses Enterobacteriaceae family member by $50 \%$, but favors rapid proliferation of Pseudomonadales to $46 \%$ of the total community, where we observed dominant association of Pesudomonas sp., Acinetobacter johnsonii; Acinetobacter rhizosphaerae, and other members from Alpha-proteobacteria family such as Sphingobium sp., Gluconacetobacter diazotrophicus, Achromobacter sp., Sphingomonas azotifigens, Methylobacterium sp. as well as Beta-proteobacteria-Burkholderiales family members such as Acidovorex sp., Delftia ramlibacter; Janthinobacterium lividum (Fig. S4a, b, c). Our microbial profiling data further suggested that blood meal significantly alters the abundance of the gram-negative bacteria such as Pseudomonas and Elizabethkingia (Fig. 6), than gram-positive bacteria such as Agromonas and Rubrobacter (Actiobacteria) (Fig. S5). 

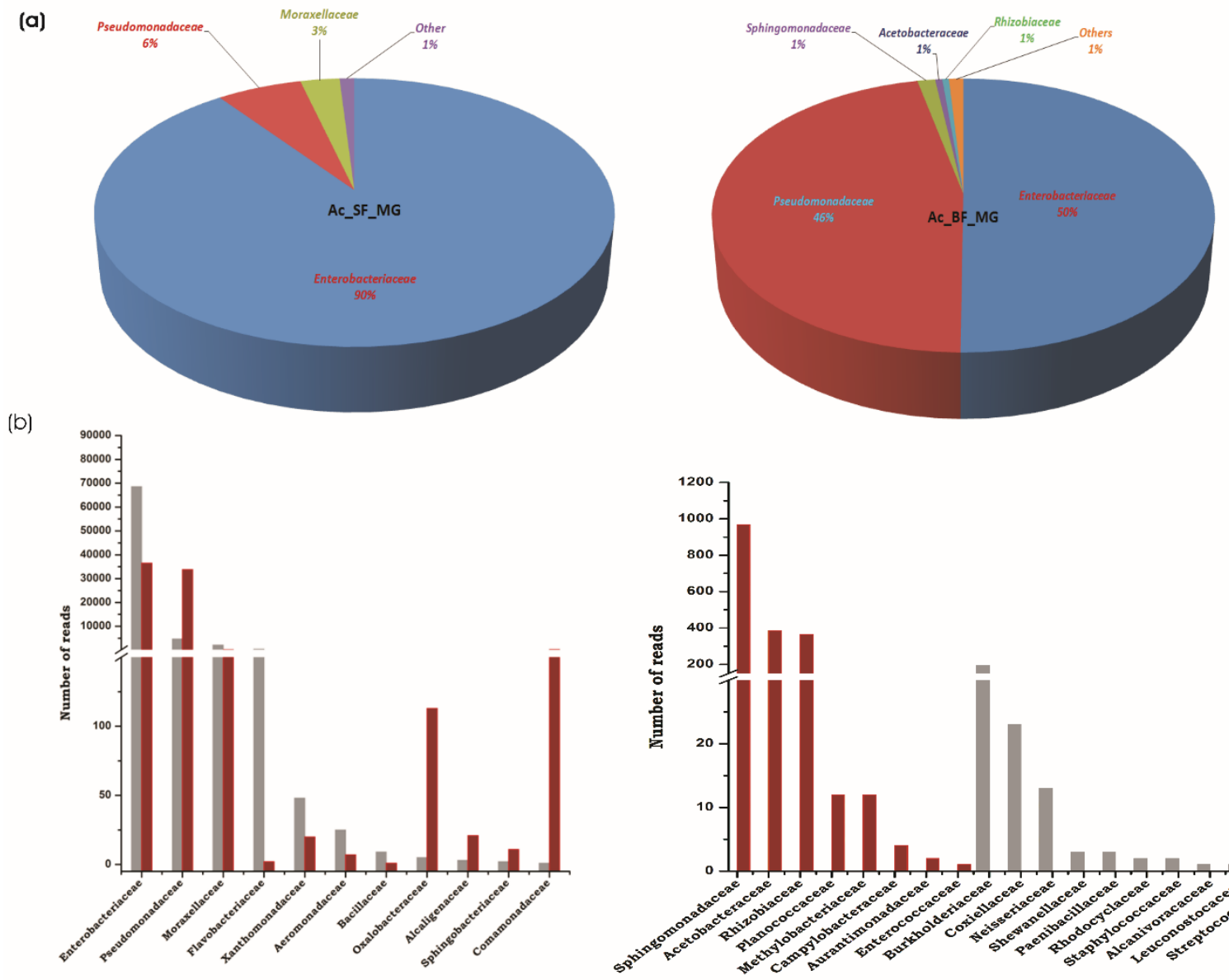

(c)
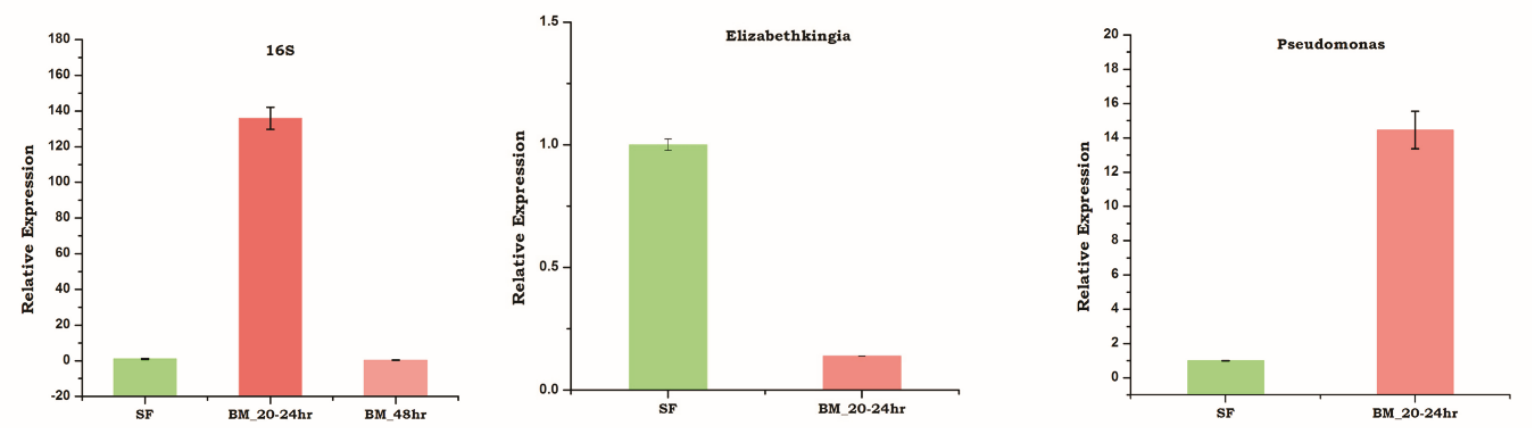

Fig. 6: Comparison of gut-metagenomes in the naïve sugar-fed and blood-fed mosquito Anopheles culicifacies: (a) Pie charts showing the major bacterial families under the two feeding status (b) Number of reads based comparative bar graphs showing common and unique families microbes (c) Relative quantitative distribution of microbiota based on 16SrRNA based expression in the midgut of $A n$. culicifacies in response to sugar and post blood feeding (20-24hrPBM, 48hr PBM); Relative abundance of Elizabethkingia and Pseudomonas sp. bacteria in sugar-fed and blood-fed (20-24hr PBM) condition.

Although the correlation of microbiome-gut-brain axis communication in the blood-feeding mosquitoes is yet not fully established, however, we opined that amino-acids resulting from rapid digestion of protein-rich blood meal, and its metabolite products may serve as an additional potent source of neuromodulators[57]. Here, our observation of Enterobacteriaceae family member abundancy and low NTs level in the gut than the brain of naïve sugar-fed 
mosquitoes indicate the basal-level of gut-brain-axis communication is enough to maintain physiological homeostasis. However, a rapid proliferation of Pseudomonadales family members, and a multi-fold enrichment of NTs in the gut, while mild suppression of the majority of NTs in the brain except for Histamine, Tyrosine and Tryptophan of the blood feed mosquitoes suggests that members of Pseudomonas species, may likely have a neuromodulatory role in protein-rich diet-induced gut-brain-axis communication.

Furthermore, to test and evaluate the effect of gut flora removal on the neurotransmitters dynamics, we performed an absolute quantification of the potent neuroactive molecules and compared their levels in the gut and brain of the naïve and antibiotic-treated mosquitoes. A significant elevation of tryptophan and consequent downregulation of serotonin levels in both the gut and brain of aseptic non-blood fed mosquitoes (Fig. 7a, b), corroborate with the previous observations that depletion of microbial flora may significantly delimit the de-novosynthesis of serotonin, resulting in increased tryptophan concentration in the gut and brain[58]. Additionally, we also observed that antibiotic treatment not only caused a notable increase in histidine and histamine levels in both the gut and brain, also favored an exclusive induction of Dopa, and significant enrichment of GABA in the gut of the aseptic mosquitoes (Fig. 7a, b).

Together, these data indicated that gut bacteria removal may also influence the systemic level of amino acid concentration (Fig. 7a, b).

To test how blood-feeding influences gut-brain axis communication, again we quantified and compared the level of the neurotransmitters of naïve and antibiotic-treated blood-fed mosquitoes. A similar pattern of NTs synthesis was observed in both naïve blood-fed and antibiotic-treated blood-fed mosquitoes, but the level of modulation is heightened in antibiotictreated blood-fed gut and brain (Fig. S7, Table S4). To further support the above observation, we also monitored and compared the expression patterns of neurotransmitter receptor genes (Glycine R, glutamate R, serotonin R, dopamine R), insulin-like-peptide, and one of the junction protein gene (lachesin) in the gut and brain of naïve vs. antibiotic-treated mosquitoes (Fig. 7c). Consistent with NT quantitative data, the respective receptor genes also showed a significant difference in their abundance throughout the gut-brain axis. We also noticed a differential expression pattern of ILP3, ARMAA (Aromatic-L-amino-acid decarboxylase/serotonin synthesizing enzyme), and lachesin transcript between naïve and antibiotic-treated mosquitoes undergoing metabolic switch event (Fig. 7c).

With our current data, we propose that a bi-directional gut-brain axis communication may exist to manage complex gut immune-physiological responses via gut-microbiome association during the blood meal digestion process in gravid females. Although, it is yet to clarify how this cross-talk directly influences brain-specific responses such as mood and cognition. 
(a)

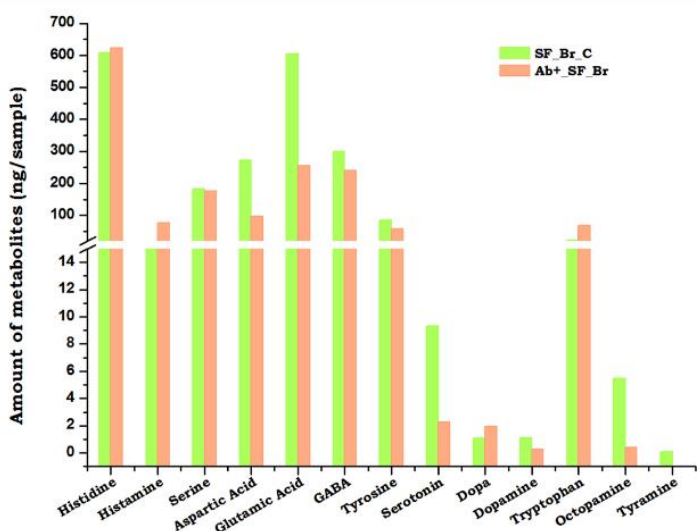

(c)
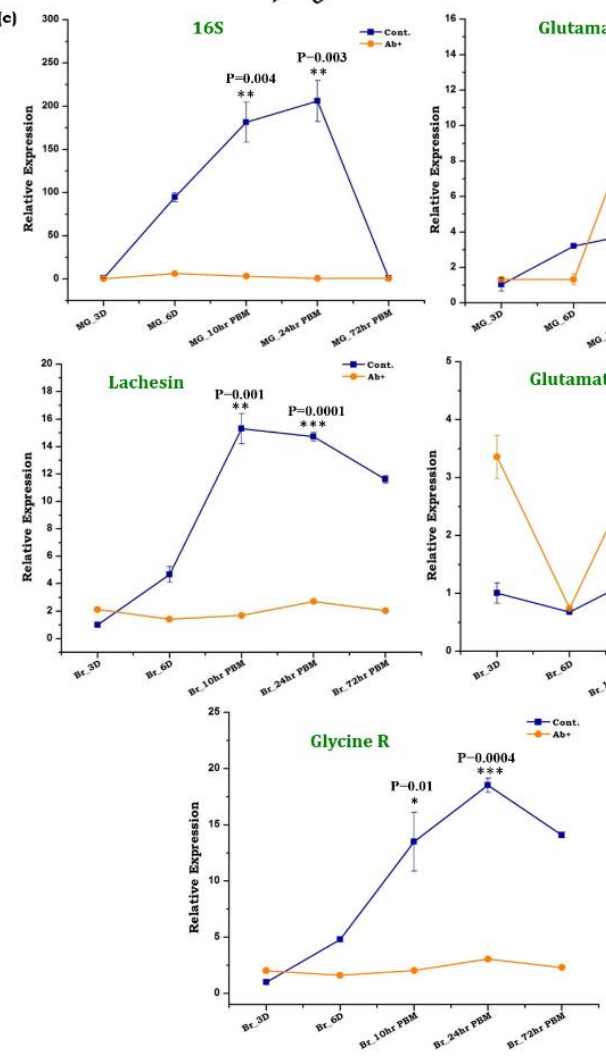

Glutamate Receptor $\quad:-$ - cont
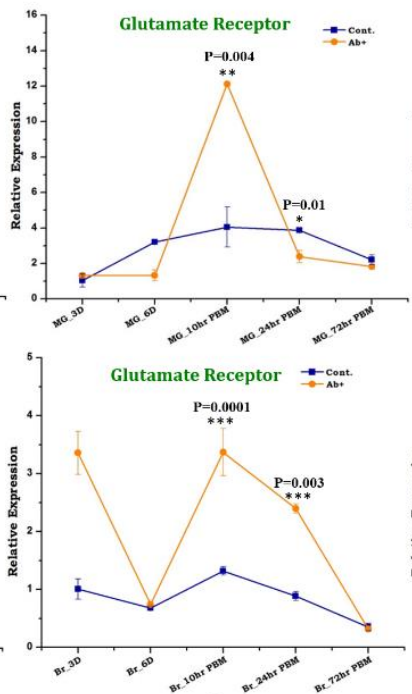
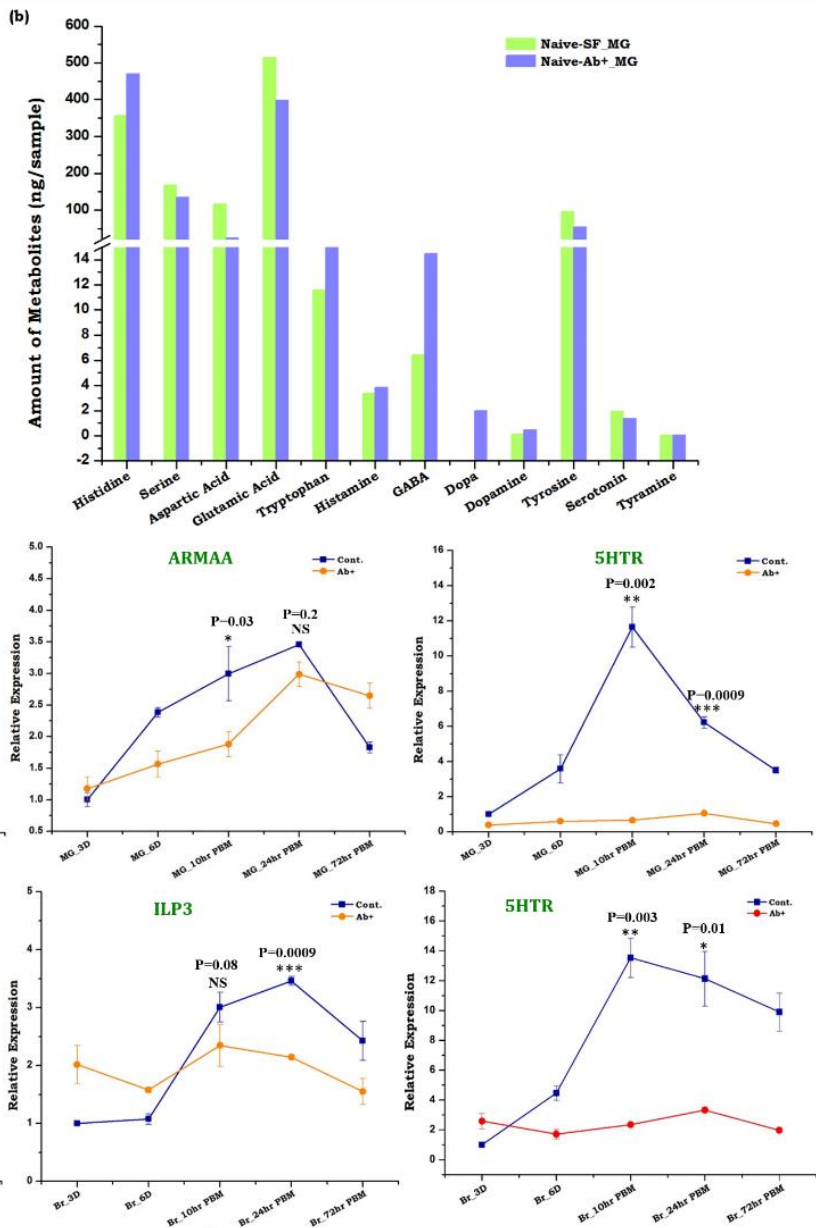

Fig. 7: Establishing Microbiome-Gut-Brain-Axis (MGB) communication in mosquitoes. (a) Absolute quantification of the neurotransmitters (NT) in the brain tissues of naïve sugar-fed and antibiotic-treated mosquitoes ( $\mathrm{n}=65, \mathrm{~N}=2$ ); (b) Quantitative estimation of the neurotransmitters (NT) in the gut tissues of naïve sugar-fed and antibiotic-treated mosquitoes. Statistically significant differences in the amount of metabolites were tested by $p$-values $(\mathrm{p} \leq 0.005)$ that are deduced by twoway ANOVA and Tukey's test, $(\mathrm{n}=50, \mathrm{~N}=2)$; (c) Relative expression profiling of the $16 \mathrm{~S}$ gene to show the population of microbial flora and other neuro-transcripts in the gut and brain of naïve and antibiotic-treated mosquitoes undergoes metabolic switch. Statistical significance of differences of the respective genes in control (without antibiotic) and aseptic mosquitoes (antibiotic-treated) were tested by the $\mathrm{t}$-test. ( $\mathrm{n}=$ number of mosquitoes from which the respective tissue was dissected and pooled for each independent experiment; $\mathrm{N}=$ number of biological replicates). 
The mosquito brain maintains basal immunity: The immune system plays a crucial role in maintaining brain health by protecting it from both external and internal stress [59]. Since the central nervous system and the immune system are the most energy-consuming organs, we consider that the immune system may play an important role to overcome blood-meal-induced metabolic stress, such as oxidative stress, osmotic stress, and elevated levels of dietary heme molecules. To trace the possible linkage of the brain-immune function, we identified and cataloged a total of 913 immune transcripts from brain tissue transcriptome data (Fig. 8a). Among the 18 classified immune family proteins, autophagy, CLIP-domain serine proteases, and peroxidases were observed the most predominant, accounting for more than $50 \%$ of the total immune transcripts. Furthermore, a comparative transcript abundance analysis showed that blood meal may cause a moderate change in the immune transcript expression (Fig. 8b). Increased percentage of peroxidases and CLIP-domain serine protease transcripts in the bloodfed brain suggested that these immune transcripts may prevent brain tissue from oxidative stress-induced damage and facilitate its recovery (Fig. 8b). Further, functional analysis of the immune transcripts in the central nervous system may unravel the novel regulatory mechanism of the immune genes to maintain the brain in shape.

(a)

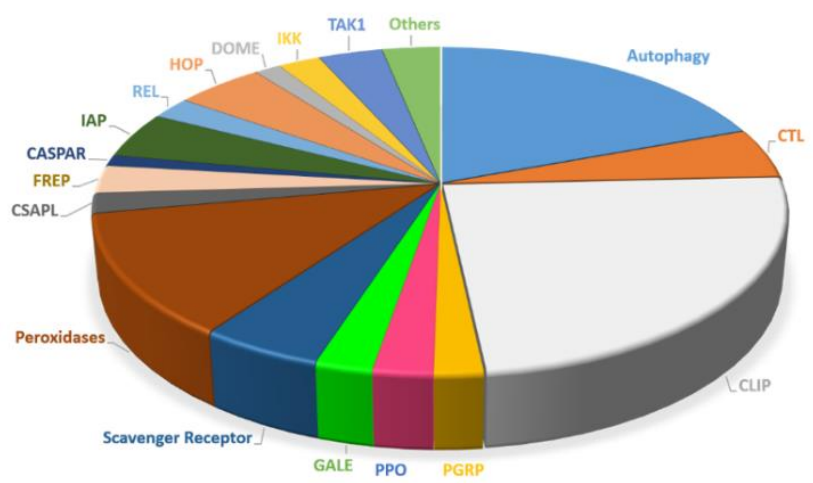

(b)

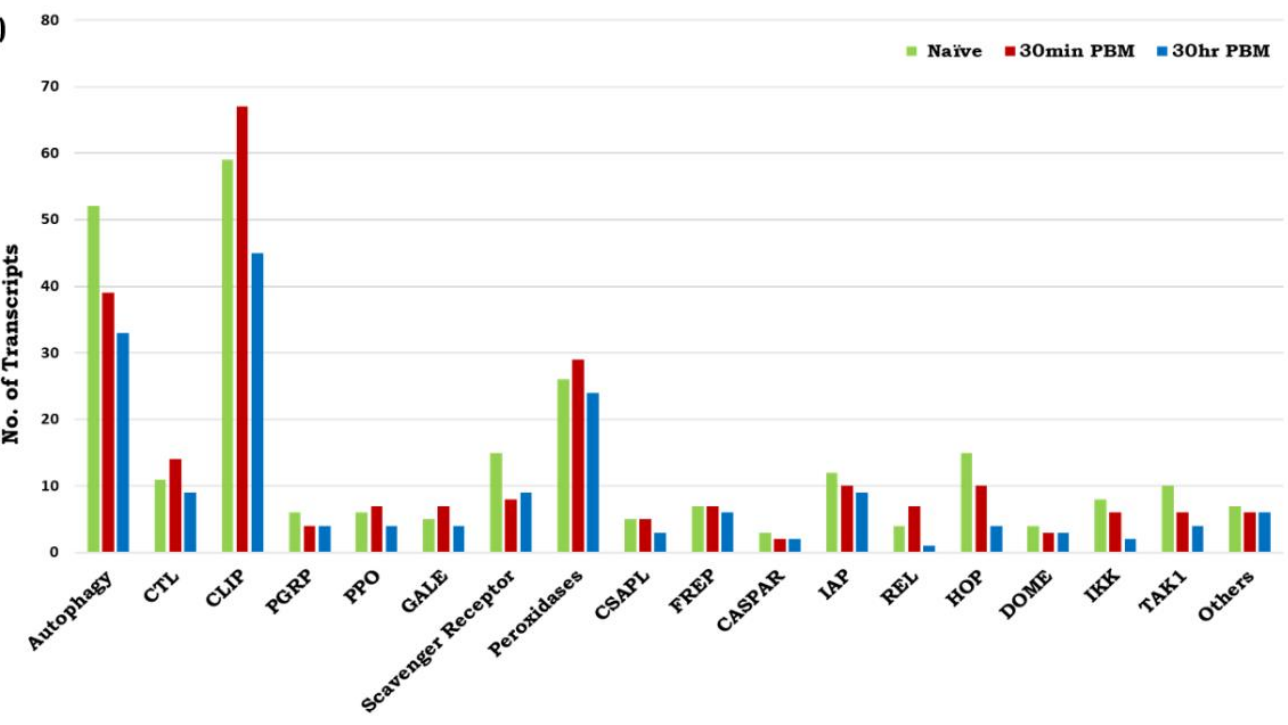

Fig. 8: Molecular catalog of brain-specific immune transcripts. (a) Molecular catalog of the different classes of immune genes expressed in brain tissue; (b) Differential expression patterns of the brain immunome as determined by the number of sequences that appeared in each RNA-Seq data of naïve and blood-fed mosquito brains. 


\section{Discussion:}

Host-seeking and blood-feeding behavior evolution make it difficult to resolve the complexity of decision-making neuro-actions in hematophagous insects[3]. Recently, Benjamin J. Matthews et. al., cataloged hundreds of genes that are differentially expressed in the blood-fed brain[60], of which the brain-encoded neuropeptide $\mathrm{Y}$ has been suggested to play a crucial role in host-seeking suppression following blood feeding[4]. But, in-depth analysis of the gutmetabolic-switch-mediated modulation of brain function is unexplored. Our study attempts to establish a molecular relationship of gut-brain-axis (GBA) communication, and explore a possible functional correlation of gut-endosymbionts on neuro-transmitters dynamics influencing GBA communication.

Gut-metabolic switch modulates the brain's energy metabolism and functional engagement: To understand that how the engorgement of the gut with blood meal modulate brain functioning, we performed a comparative RNA-Seq analysis of naïve sugar-fed and blood-fed of adult female mosquitoes' brain in An. culicifacies. In contrast to the pre-blood meal olfactory responses, which are significantly influenced by age/sex/circadian even in the absence of host-exposure[1, 29, 30], we did not observe any significant alteration of neuromodulator genes expression in the non-blood-fed (host-unexposed) aging An. culicifacies mosquitoes. The onset of host-seeking behavior coincides with the age-dependent gradual change in the relative abundance of gene transcripts and increase in sensitivity of the olfactory sensory neurons (OSNs), where older females are likely to be more responsive to salient human odorants, and hence active host-seeker than teneral young female mosquitoes[61, 62]. Thus, our observation of a limited change in the neuro-modulatory genes expression in the mosquito An. culicifacies, suggests that cognitive learning and memory response towards host-attraction are poorly developed until mosquitoes are exposed to hosts.

Post-blood-feeding an exclusive induction of oxidation-reduction family proteins and a comparative pathway analysis predicts that blood meal may enhance the brain's energy metabolic activities. Shreds of evidence from Drosophila, vertebrates, and limited studies in mosquitoes also suggest that altered metabolic physiology influences the cross-talk between the brain and peripheral tissues for the maintenance of systemic energy homeostasis[12, 35, 55, 63-65]. To perform this action, continuous neuronal stimulation is required, which consequently increases the energy demand of the brain[64, 66]. An enrichment of the fructosemannose metabolic pathway and persistent elevation of PGC-1 and oxoglutarate dehydrogenase gene provides evidence of escalated energy metabolism and enhanced mitochondrial activity in blood-fed mosquitoes brain[31, 32]. In this context, it is plausible to propose that hyper mitochondrial activity may increase the ROS level which could have a deleterious impact on neuro action. Our observation of the unique appearance of the pentose phosphate pathway and glutathione peroxidase transcript (Oxidation-reduction category gene), along with the upregulation of CLIP-domain serine proteases and peroxidases immune transcripts may attribute to the scavenging of ROS generated due to enhanced mitochondrial activity. Moreover, blood-meal-induced expression of amino acid transporters and trehalose transporter indicated that both trehalose and amino acids may serve as a raw material for enhanced energy metabolism. Furthermore, we also observed a significant alteration of transcripts involved in intracellular signaling than neurotransmitter receptors in the blood-fed mosquitoes' brains. Together these data, we hypothesize that an internal nutritional stimulus may shift brain engagement from external communication to inter-organ management, which requires a rapid and continuous synaptic transmission, neurotransmitter recycling, and axodendritic transport, resulting in enhanced energy metabolism in the brain[64, 65]. 
Neuromodulatory responses establish brain-distant organ communication: To support our hypothesis, we profiled a selected class of neuromodulators, neuropeptides, and neurohormones gene expression in the brain and correlated their impact on distant organs. Corresponding to the innate physiological status, we observed a time-dependent change in the expression pattern of the respective transcripts in the brain, and other targeted tissues of mosquito such as midgut, Malpighian tubule, and ovaries. But, in turn, how these neuromodulatory responses reinforce brain action remains unknown. Recent studies in Drosophila suggest that leukokinin neuropeptide regulates protein diet-induced post-prandial sleep and minimized movement[67]. We also observed a transient increase in leukokinin, and its receptor gene in the brain, and sustained up-regulation of the leukokinin receptor gene in the gut till 30h of blood-feeding. These data support the idea that until the blood meal gets digested in the gut, the brain may undergo 'food coma' and restrict external communication, but may actively engage in managing inter-organ communications (through ILPs and other neuro-hormones e.g. DH44, OEH, etc.). Compared to the brain, significant modulation of neuro-modulators, and sustained expression even in the gut of decapitated blood-fed mosquitoes, further suggested a specialized ability of the gut to serve as "second brain" possibly to share and minimize the function of the primary brain [16]. Taken together, we interpret that gut-metabolic-switching may favor the establishment of a bidirectional 'gutbrain-axis' communication in the gravid female mosquitoes, though the detailed molecular mechanism is yet to unravel.

Neurotransmitter signaling and microbiome alteration influences Gut-brain-axis communications: Neurotransmitters, including both biogenic amines and amino acids, are well-known endogenous chemicals, that influence rapid inter-organ signal transmission and decision-making abilities[68, 69]. To clarify and establish a possible functional correlation between the gut metabolic switch and gut-brain axis communication, we quantified the levels of neurotransmitters secreted from both gut and brain tissues. When compared to the naïve sugar-fed status, an unusual and paramount shift from the brain to the gut was observed for almost all the neurotransmitter levels after blood feeding. A significant upregulation of aspartic acid, glutamic acid, histidine, and histamine levels in blood-fed mosquito gut and brain may be a consequence of the rapid degradation of protein-rich blood meal in the mosquito gut[70].

Although the effect of tyrosine enrichment in the brain is intriguing, however, an undetectable level of tyrosine in the gut supports previous findings that the scavenging of toxic tyrosine from the gut is essential for the safeguarding journey of blood-fed mosquitoes[71]. A substantial body of literature also suggests that the biogenic amines such as dopamine and serotonin are the critical regulators of feeding, host-seeking, and cognitive functions[72-76]. Thus, it would be worth testing whether an increase in the precursor molecules of dopamine i.e. tyrosine, in the blood-fed mosquito's brain, improves the cognitive power of the mosquito's host-seeking and blood-feeding behavioral activities. Likewise, an enrichment of tryptophan, a precursor of serotonin, may favor the minimization of the host-seeking behavioral activities of gravid females (Fig. 5b)[77]. Additionally, 25-fold upregulation of GABAergic neurotransmission upon blood-feeding in the midgut highlights its possible function in the regulation of innate immune response by activating the autophagy due to gut flora expansion (Fig. 5c)[78, 79].

Appreciably, a recent term 'psycobiotics', which aims to examine the influential effect of the microbiome on the gut-brain axis communication, is common to vertebrate's neurobiology, but insects' communities are least attended[80, 81]. In vertebrates, studies suggested that mediators 
of the microbiota-gut-brain-axis communication are usually affected by microbial metabolism which includes short-chain fatty acids such as butyrate, neurotransmitters e.g. serotonin and $\gamma-$ aminobutyric acid (GABA), hormones e.g. cortisol, and other immune system modulators e.g. quinolinic acid[82]. Further research on vertebrates and fruit flies indicated that gut microbiota influences several behavioral physiologies, including host metabolism, appetite, mood, sensory perception, and cognition[83-87]. Recent studies in flies also demonstrated that gut commensal bacteria and the composition of dietary amino acid supplements greatly influence in shaping behavioral responses such as food choice and olfactory guided foraging decisions [86, 88, 89]. However, studies on mosquitoes' gut-symbionts are predominantly limited to their impact on parasite growth and their potentiality for para-transgenic approaches[90].

Our observation of a rapid proliferation of Pseudomonas bacterial sp. in the gut of blood-fed mosquitoes may likely due to increased consumption of dietary Tryptophan for the synthesis of serotonin, correlating a possible cause for the suppression of appetite (Fig. 6a, c \& Fig. 5c) [91, 92]. Additionally, a significant reduction of the excitatory neurotransmitters Glutamic acid and Aspartic acid in the brain may help to restrict the foraging behavior in gravid females[93]. However, intriguingly a parallel thousand-fold increase in aspartic acid in the gut is whether a result of gut-microbial metabolism and/or any correlation with gut-neuroendocrine regulation for egg development remains uncertain. Previous biochemical characterization of Locust's vitellogenin protein showed that it carries high content of aspartic acid, glutamic acid, and leucine[94]. An independent in-silico amino-acid composition analysis of mosquito An. culicifacies vitellogenin protein (AEO51020.1) also revealed a high content of aspartic acid (6.2\%), glutamic acid (6.7\%), phenylalanine (7.6\%), and serine (8.7\%). Furthermore, previous literature indicated that disruption of gut-microbiota by antibiotic treatment not only reduces the anti-Plasmodium immunity but also hinder the egg development in the blood-feeding mosquitoes[21, 95]. Therefore, we correlate that blood-meal-induced gutmicrobial metabolism and activation of the vitellogenesis process may sequester the majority of amino acids to nurture the eggs[52]. But, the remaining fraction of amino acids either serves as an energy reservoir in the fat body [52] or functions as a neurotransmitter, possibly to maintain gut-brain-axis communication, though further studies are needed to prove these presumptions.

A noteworthy modulation of gut neurotransmitters reinforces us to test how the blood-meal induced rapid proliferation of gut flora also influence gut-brain axis communications. We disrupted the gut symbionts by providing an antibiotic diet supplement to the newly emerged mosquitoes for 4-5 days and observed a significant difference in the abundance of neurotransmitters in both the gut and the brain. Surprisingly, we also noticed that aseptic adult female mosquitoes carry assertive feeding behavior towards a vertebrate host (personal observation). In animals, an earlier study showed that germ-free mice exhibited stress-induced altered behavioral response, which was restored after complete microbiota recolonization[96]. Studies further signify that the microbial antigens such as lipopolysaccharide (LPS) and lipoteichoic acids generated in response to antibiotic treatment elicit immune responses and favors early development of the gut-brain axis communication via gut neuronal sensing [97]. In the mosquito An. stephensi, the antibiotic treatment also enhances the transcriptional responses of gut-immune peptides, but the effect on neuro-sensing remains unclarified[98]. We interpret that a higher abundance of histamine in the brain and GABA in the gut of antibiotictreated mosquitoes may be accountable for the enhanced host-seeking behavioral activities, either directly through neuro-stimulation or indirectly through the vagal pathway[99, 100]. Furthermore, blood-feeding to aseptic mosquitoes resulted in a multi-fold up-regulation of serine and glutamic acid suggesting a limited usage of the respective amino acids, in the lack 
of a microbial population (Fig. S7) (Table S4), which consumes crucial amino acids to synthesize the building blocks of bacterial cell wall components in the healthy blood-fed mosquitoes[101, 102].

\section{Conclusion:}

The current investigation provides a novel insight that how gut-metabolic-switch-induced transcriptional modulation shifts mosquito's brain engagement from external communication (pre-blood meal host-seeking and host selection) to manage inter-organ communication (postblood meal physiological homeostasis) for the fitness of the mosquitoes. To the best of our knowledge, our data provide initial evidence that correlates the potential role of gut endosymbionts in microbiome-gut-brain-axis communication. We believe our conceptual framework may be valuable to modify mosquitoes' olfactory perception and cognition through the alteration of gut bacteria, and hence for new vector control tool development.

Funding statement: This laboratory work was supported by the Indian Council of Medical Research (ICMR), the Government of India (No.3/1/3/ICRMR-VFS/HRD/2/2016), and Tata Education and Development Trust (Health-NIMR-2017-01-03/AP/db). Tanwee Das De is the recipient of the ICMR-Post Doctoral Fellowship Scheme (3/1/3/PDF(18)/2018-HRD). Punita Sharma is recipient of ICMR-Research Associateship award (Fellowship/52/2019-ECD-II). The funders had no role in study design, data collection, and analysis, decision to publish, or preparation of the manuscript.

Data deposition: The sequencing data were deposited to National Centre for Biotechnology Information (NCBI) Sequence Reads Archive (SRA) system (BioProject accessions: PRJNA555826; BioSample accessions: SRR9853884 for Ac-Br-SF, SRR9853885 for Ac-Br30Min, and SRR9853883 for Ac-Br-30hrs).

Authors contribution statement: TDD, PS, KCP, YH, RKD: Conceived and designed the experiments: TDD, PS, ST, DS, VS, CR, SK, ST, JR; RD; contributed to design and performing the experiments, data acquisition, writing and editing; TDD, PS, YH, KCP, RKD: data analysis and interpretation, data presentation, contributed reagents/ materials/analysis tools, wrote, reviewed, edited, and finalized MS. All authors read and approved the final manuscript.

Competing interest statement: The authors declare no conflicts of interest

\section{Acknowledgment}

We thank insectary staff members for mosquito rearing. We also thank Kunwarjeet Singh for technical assistance in the laboratory. Finally, we are thankful to Xceleris Genomics, Ahmedabad, India for generating NGS sequencing data and DNAXperts, Noida, Utter Pardesh for metagenomic data generation and analysis. We thank CCAMP Metabolomics Facility for performing neurotransmitter (NT) analysis. We are grateful to Padma Ramakrishnan, Technology Scientist, Mass Spectrometry Facility - Centre for Cellular and Molecular Platforms, Bengaluru for her inputs in the manuscript by providing the details of LC/MS-based NT analysis and also thank her for troubleshooting during our study. 


\section{References:}

1. De T Das, Thomas T, Verma S, et al (2018) A synergistic transcriptional regulation of olfactory genes drives blood-feeding associated complex behavioral responses in the mosquito anopheles culicifacies. Front Physiol. https://doi.org/10.3389/fphys.2018.00577

2. Potter CJ (2014) Stop the biting: Targeting a mosquito's sense of smell. Cell 156:878881

3. Das De T, Dixit R (2020) Neuro-Olfactory Regulation and Salivary Actions: A Coordinated Event for Successful Blood-Feeding Behavior of Mosquitoes. In: Dysfunction of Olfactory System [Working Title]

4. Duvall LB, Ramos-Espiritu L, Barsoum KE, et al (2019) Small-Molecule Agonists of Ae. aegypti Neuropeptide Y Receptor Block Mosquito Biting. Cell. https://doi.org/10.1016/j.cell.2018.12.004

5. Takken W, Van Loon JJA, Adam W (2001) Inhibition of host-seeking response and olfactory responsiveness in Anopheles gambiae following blood feeding. J Insect Physiol 47:303-310. https://doi.org/10.1016/S0022-1910(00)00107-4

6. Beyenbach K, Petzel D (2017) Diuresis in Mosquitoes: Role of a Natriuretic Factor. Physiology. https://doi.org/10.1152/physiologyonline.1987.2.5.171

7. Beyenbach KW (2012) A dynamic paracellular pathway serves diuresis in mosquito Malpighian tubules. Ann N Y Acad Sci. https://doi.org/10.1111/j.17496632.2012.06527.x

8. Sanders HR, Evans AM, Ross LS, Gill SS (2003) Blood meal induces global changes in midgut gene expression in the disease vector, Aedes aegypti. Insect Biochem Mol Biol 33:1105-1122. https://doi.org/10.1016/S0965-1748(03)00124-3

9. Badisco L, Van Wielendaele P V., Broeck J Vanden (2013) Eat to reproduce: A key role for the insulin signaling pathway in adult insects. Front. Physiol. 4 AUG

10. Liu Q, Jin LH (2017) Organ-to-Organ Communication: A Drosophila Gastrointestinal Tract Perspective. Front Cell Dev Biol. https://doi.org/10.3389/fcell.2017.00029

11. Duvall LB (2019) Mosquito Host-Seeking Regulation: Targets for Behavioral Control. Trends Parasitol.

12. Droujinine IA, Perrimon N (2016) Interorgan Communication Pathways in Physiology: Focus on Drosophila . Annu Rev Genet. https://doi.org/10.1146/annurev-genet-121415122024

13. Gulia-Nuss M, Robertson AE, Brown MR, Strand MR (2011) Insulin-like peptides and the target of rapamycin pathway coordinately regulate blood digestion and egg maturation in the mosquito Aedes aegypti. PLoS One. https://doi.org/10.1371/journal.pone.0020401

14. Fadda M, Hasakiogullari I, Temmerman L, et al (2019) Regulation of Feeding and Metabolism by Neuropeptide F and Short Neuropeptide F in Invertebrates. Front Endocrinol (Lausanne). https://doi.org/10.3389/fendo.2019.00064

15. Christ P, Reifenrath A, Kahnt J, et al (2017) Feeding-induced changes in allatostatin-A and short neuropeptide $\mathrm{F}$ in the antennal lobes affect odor-mediated host seeking in the yellow fever mosquito, Aedes aegypti. PLoS One. https://doi.org/10.1371/journal.pone.0188243

16. Mayer EA (2011) Gut feelings: The emerging biology of gut-"brain communication. Nat. Rev. Neurosci.

17. Ridaura V, Belkaid Y (2015) Gut microbiota: The link to your second brain. Cell 
18. Fülling C, Dinan TG, Cryan JF (2019) Gut Microbe to Brain Signaling: What Happens in Vagus.... Neuron

19. Forsythe P, Kunze WA (2013) Voices from within: Gut microbes and the CNS. Cell. Mol. Life Sci.

20. Lampe L, Jentzsch M, Kierszniowska S, Levashina EA (2019) Metabolic balancing by miR-276 shapes the mosquito reproductive cycle and Plasmodium falciparum development. Nat Commun. https://doi.org/10.1038/s41467-019-13627-y

21. Romoli O, Gendrin M (2018) The tripartite interactions between the mosquito, its microbiota and Plasmodium. Parasites and Vectors

22. Sharma P, Sharma S, Mishra AK, et al (2015) Unraveling dual feeding associated molecular complexity of salivary glands in the mosquito Anopheles culicifacies. Biol Open 4:1002-15. https://doi.org/10.1242/bio.012294

23. Livak KJ, Schmittgen TD (2001) Analysis of relative gene expression data using realtime quantitative PCR and the 2(-Delta Delta C(T)) Method. Methods 25:402-8. https://doi.org/10.1006/meth.2001.1262

24. Natarajan N, Ramakrishnan P, Lakshmanan V, et al (2015) A quantitative metabolomics peek into planarian regeneration. Analyst. https://doi.org/10.1039/c4an02037e

25. Ramesh D, Brockmann A (2019) Mass Spectrometric Quantification of Arousal Associated Neurochemical Changes in Single Honey Bee Brains and Brain Regions. ACS Chem Neurosci. https://doi.org/10.1021/acschemneuro.8b00254

26. Sharma P, Rani J, Chauhan C, et al (2020) Altered Gut Microbiota and Immunity Defines Plasmodium vivax Survival in Anopheles stephensi. Front Immunol. https://doi.org/10.3389/fimmu.2020.00609

27. Kuczynski J, Stombaugh J, Walters WA, et al (2011) Using QIIME to analyze 16S rRNA gene sequences from microbial communities. Curr Protoc Bioinforma. https://doi.org/10.1002/0471250953.bi1007s36

28. Huson DH, Auch AF, Qi J, Schuster SC (2007) MEGAN analysis of metagenomic data. Genome Res. https://doi.org/10.1101/gr.5969107

29. De T Das, Sharma P, Rawal C, et al (2017) Sex-specific molecular responses of quickto-court protein in Indian malarial vector Anopheles culicifacies : conflict of mating versus blood feeding behaviour. Heliyon e00361. https://doi.org/10.1016/j.heliyon.2017.e00361

30. Das De T, Hasija Y, Dixit R (2018) Transcriptional responses of attractin gene in the mosquito Anopheles culicifacies: A synergistic neuro-olfactory regulation. J Vector Borne Dis. https://doi.org/10.4103/0972-9062.242569

31. Austin S, St-Pierre J (2012) PGC1 and mitochondrial metabolism - emerging concepts and relevance in ageing and neurodegenerative disorders. $J$ Cell Sci. https://doi.org/10.1242/jcs.113662

32. Lin J, Handschin C, Spiegelman BM (2005) Metabolic control through the PGC-1 family of transcription coactivators. Cell Metab.

33. Liang H, Ward WF (2006) PGC-1 $\alpha$ : a key regulator of energy metabolism. Adv Physiol Educ. https://doi.org/10.1152/advan.00052.2006

34. Shukla E, Thorat LJ, Nath BB, Gaikwad SM (2015) Insect trehalase: Physiological significance and potential applications. Glycobiology

35. Mattila J, Hietakangas V (2017) Regulation of carbohydrate energy metabolism in Drosophila melanogaster. Genetics. https://doi.org/10.1534/genetics.117.199885

36. Hou Y, Wang XL, Saha TT, et al (2015) Temporal Coordination of Carbohydrate Metabolism during Mosquito Reproduction. PLoS Genet. https://doi.org/10.1371/journal.pgen.1005309

37. Brown MR, Clark KD, Gulia M, et al (2008) An insulin-like peptide regulates egg 
maturation and metabolism in the mosquito Aedes aegypti. Proc Natl Acad Sci. https://doi.org/10.1073/pnas.0800478105

38. Sharma A, Nuss AB, Gulia-Nuss M (2019) Insulin-like peptide signaling in mosquitoes: The road behind and the road ahead. Front. Endocrinol. (Lausanne).

39. Vogel KJ, Brown MR, Strand MR (2015) Ovary ecdysteroidogenic hormone requires a receptor tyrosine kinase to activate egg formation in the mosquito Aedes aegypti . Proc Natl Acad Sci. https://doi.org/10.1073/pnas.1501814112

40. Liesch J, Bellani LL, Vosshall LB (2013) Functional and Genetic Characterization of Neuropeptide Y-Like Receptors in Aedes aegypti. PLoS Negl Trop Dis 7:. https://doi.org/10.1371/journal.pntd.0002486

41. Arsic D, Guerin PM (2008) Nutrient content of diet affects the signaling activity of the insulin/target of rapamycin/p70 S6 kinase pathway in the African malaria mosquito Anopheles gambiae. J Insect Physiol 54:1226-1235. https://doi.org/10.1016/j.jinsphys.2008.06.003

42. Piermarini PM, Esquivel CJ, Denton JS (2017) Malpighian tubules as novel targets for mosquito control. Int. J. Environ. Res. Public Health

43. Sim C, Denlinger DL (2009) A shut-down in expression of an insulin-like peptide, ILP1 , halts ovarian maturation during the overwintering diapause of the mosquito Culex pipiens. Insect Mol Biol. https://doi.org/10.1111/j.1365-2583.2009.00872.x

44. Castillo J, Brown MR, Strand MR (2011) Blood feeding and insulin-like peptide 3 stimulate proliferation of hemocytes in the mosquito Aedes aegypti. PLoS Pathog 7:. https://doi.org/10.1371/journal.ppat.1002274

45. Kersch CN, Pietrantonio P V. (2011) Mosquito Aedes aegypti (L.) leucokinin receptor is critical for in vivo fluid excretion post blood feeding. FEBS Lett. https://doi.org/10.1016/j.febslet.2011.10.001

46. Zhang Q, Denlinger DL (2011) Molecular structure of the prothoracicotropic hormone gene in the northern house mosquito, Culex pipiens, and its expression analysis in association with diapause and blood feeding. Insect Mol Biol. https://doi.org/10.1111/j.1365-2583.2010.01058.x

47. Strand MR, Brown MR, Vogel KJ (2016) Mosquito Peptide Hormones: Diversity, Production, and Function. In: Advances in Insect Physiology

48. Kinney MP, Panting ND, Clark TM (2014) Modulation of appetite and feeding behavior of the larval mosquito Aedes aegypti by the serotonin-selective reuptake inhibitor paroxetine: shifts between distinct feeding modes and the influence of feeding status. $\mathbf{J}$ Exp Biol. https://doi.org/10.1242/jeb.094904

49. Ling L, Raikhel AS (2018) Serotonin signaling regulates insulin-like peptides for growth, reproduction, and metabolism in the disease vector Aedes aegypti . Proc Natl Acad Sci. https://doi.org/10.1073/pnas.1808243115

50. Chen Q, Man Y, Li J, et al (2017) Olfactory ionotropic receptors in mosquito aedes albopictus (Diptera: Culicidae). J Med Entomol. https://doi.org/10.1093/jme/tjx063

51. Bowery NG, Smart TG (2006) GABA and glycine as neurotransmitters: A brief history. Br. J. Pharmacol.

52. Hansen IA, Attardo GM, Rodriguez SD, Drake LL (2014) Four-way regulation of mosquito yolk protein precursor genes by juvenile hormone-, ecdysone-, nutrient-, and insulin-like peptide signaling pathways. Front. Physiol.

53. Coast GM (2005) Mosquito natriuretic peptide identified as a calcitonin-like diuretic hormone in Anopheles gambiae (Giles). J Exp Biol. https://doi.org/10.1242/jeb.01760

54. Solari P, Rivelli N, De Rose F, et al (2017) Opposite effects of 5-HT/AKH and octopamine on the crop contractions in adult Drosophila melanogaster: Evidence of a double brain-gut serotonergic circuitry. PLoS One. 
https://doi.org/10.1371/journal.pone.0174172

55. Oriach CS, Robertson RC, Stanton C, et al (2016) Food for thought: The role of nutrition in the microbiota-gut-brain axis. Clin. Nutr. Exp.

56. Guégan M, Zouache K, Démichel C, et al (2018) The mosquito holobiont: fresh insight into mosquito-microbiota interactions. Microbiome

57. (1999) The Role of Protein and Amino Acids in Sustaining and Enhancing Performance

58. O'Mahony SM, Clarke G, Borre YE, et al (2015) Serotonin, tryptophan metabolism and the brain-gut-microbiome axis. Behav. Brain Res.

59. Aguilera G, Colín-González AL, Rangel-López E, et al (2018) Redox Signaling, Neuroinflammation, and Neurodegeneration. Antioxidants Redox Signal.

60. Matthews BJ, McBride CS, DeGennaro M, et al (2016) The neurotranscriptome of the Aedes aegypti mosquito. BMC Genomics. https://doi.org/10.1186/s12864-015-2239-0

61. Tallon AK, Hill SR, Ignell R (2019) Sex and age modulate antennal chemosensoryrelated genes linked to the onset of host seeking in the yellow-fever mosquito, Aedes aegypti. Sci Rep. https://doi.org/10.1038/s41598-018-36550-6

62. Omondi AB, Ghaninia M, Dawit M, et al (2019) Age-dependent regulation of host seeking in Anopheles coluzzii. Sci Rep. https://doi.org/10.1038/s41598-019-46220-w

63. Plaçais PY, De Tredern É, Scheunemann L, et al (2017) Upregulated energy metabolism in the Drosophila mushroom body is the trigger for long-term memory. Nat Commun. https://doi.org/10.1038/ncomms 15510

64. Yellen G (2018) Fueling thought: Management of glycolysis and oxidative phosphorylation in neuronal metabolism. J. Cell Biol.

65. Roh E, Song DK, Kim MS (2016) Emerging role of the brain in the homeostatic regulation of energy and glucose metabolism. Exp. Mol. Med.

66. Volkenhoff A, Weiler A, Letzel M, et al (2015) Glial glycolysis is essential for neuronal survival in drosophila. Cell Metab. https://doi.org/10.1016/j.cmet.2015.07.006

67. Murphy KR, Deshpande SA, Yurgel ME, et al (2016) Postprandial sleep mechanics in Drosophila. Elife. https://doi.org/10.7554/eLife.19334

68. Mittal R, Debs LH, Patel AP, et al (2017) Neurotransmitters: The Critical Modulators Regulating Gut-Brain Axis. J. Cell. Physiol.

69. Holzer P, Farzi A (2014) Neuropeptides and the microbiota- Gut-brain axis. Adv Exp Med Biol. https://doi.org/10.1007/978-1-4939-0897-4_9

70. Imamura T, Baldwin TO, Riggs A (1972) The amino acid sequence of the monomeric hemoglobin component from the bloodworm, Glyat liver. J Biol Chem

71. Sterkel M, Perdomo HD, Guizzo MG, et al (2016) Tyrosine Detoxification Is an Essential Trait in the Life History of Blood-Feeding Arthropods. Curr Biol. https://doi.org/10.1016/j.cub.2016.06.025

72. French AS, Simcock KL, Rolke D, et al (2014) The role of serotonin in feeding and gut contractions in the honeybee. J Insect Physiol 61:8-15. https://doi.org/10.1016/j.jinsphys.2013.12.005

73. Kamhi JF, Arganda S, Moreau CS, Traniello JFA (2017) Origins of Aminergic Regulation of Behavior in Complex Insect Social Systems. Front Syst Neurosci 11:. https://doi.org/10.3389/fnsys.2017.00074

74. Friedman DA, Pilko A, Skowronska-Krawczyk D, et al (2018) The Role of Dopamine in the Collective Regulation of Foraging in Harvester Ants. Food Sci Hum Wellness. https://doi.org/10.1016/j.isci.2018.09.001

75. Vinauger C, Lahondère C, Wolff GH, et al (2018) Modulation of Host Learning in Aedes aegypti Mosquitoes. Curr Biol. https://doi.org/10.1016/j.cub.2017.12.015

76. Vinauger C (2019) Vector cognition and neurobiology. Curr. Opin. Insect Sci.

77. Ngai M, Shoue DA, Loh Z, McDowell MA (2019) The pharmacological and functional 
characterization of the serotonergic system in Anopheles gambiae and Aedes aegypti: influences on flight and blood-feeding behavior. Sci Rep. https://doi.org/10.1038/s41598-019-38806-1

78. Kim JK, Kim YS, Lee HM, et al (2018) GABAergic signaling linked to autophagy enhances host protection against intracellular bacterial infections. Nat Commun. https://doi.org/10.1038/s41467-018-06487-5

79. Zhu Y, Zhang R, Zhang B, et al (2017) Blood meal acquisition enhances arbovirus replication in mosquitoes through activation of the GABAergic system. Nat Commun. https://doi.org/10.1038/s41467-017-01244-6

80. Sarkar A, Lehto SM, Harty S, et al (2016) Psychobiotics and the Manipulation of Bacteria-Gut-Brain Signals. Trends Neurosci.

81. Montiel-Castro AJ, González-Cervantes RM, Bravo-Ruiseco G, Pacheco-López G (2013) The microbiota-gut-brain axis: neurobehavioral correlates, health and sociality. Front Integr Neurosci. https://doi.org/10.3389/fnint.2013.00070

82. Parker A, Fonseca S, Carding SR (2020) Gut microbes and metabolites as modulators of blood-brain barrier integrity and brain health. Gut Microbes

83. van de Wouw M, Schellekens H, Dinan TG, Cryan JF (2017) Microbiota-Gut-Brain Axis: Modulator of Host Metabolism and Appetite. J Nutr. https://doi.org/10.3945/jn.116.240481

84. Kawase T, Nagasawa M, Ikeda H, et al (2017) Gut microbiota of mice putatively modifies amino acid metabolism in the host brain. $\mathrm{Br} \mathrm{J}$ Nutr. https://doi.org/10.1017/S0007114517000678

85. Westfall S, Lomis N, Prakash S (2018) Longevity extension in Drosophila through gutbrain communication. Sci Rep. https://doi.org/10.1038/s41598-018-25382-Z

86. Akami M, Andongma AA, Zhengzhong C, et al (2019) Intestinal bacteria modulate the foraging behavior of the oriental fruit fly Bactrocera dorsalis (Diptera: Tephritidae). PLoS One. https://doi.org/10.1371/journal.pone.0210109

87. Gareau MG (2014) Microbiota-gut-brain axis and cognitive function. Adv Exp Med Biol. https://doi.org/10.1007/978-1-4939-0897-4_16

88. Leitão-Gonçalves R, Carvalho-Santos Z, Francisco AP, et al (2017) Commensal bacteria and essential amino acids control food choice behavior and reproduction. PLoS Biol. https://doi.org/10.1371/journal.pbio.2000862

89. Wong ACN, Wang QP, Morimoto J, et al (2017) Gut Microbiota Modifies OlfactoryGuided Microbial Preferences and Foraging Decisions in Drosophila. Curr Biol. https://doi.org/10.1016/j.cub.2017.07.022

90. Blumberg BJ, Short SM, Dimopoulos G (2015) Employing the Mosquito Microflora for Disease Control. In: Genetic Control of Malaria and Dengue

91. Kaur H, Bose C, Mande SS (2019) Tryptophan Metabolism by Gut Microbiome and Gut-Brain-Axis: An in silico Analysis. Front Neurosci. https://doi.org/10.3389/fnins.2019.01365

92. Jenkins TA, Nguyen JCD, Polglaze KE, Bertrand PP (2016) Influence of tryptophan and serotonin on mood and cognition with a possible role of the gut-brain axis. Nutrients

93. Taylor P, Brown JH (1943) Basic Neurochemistry: Molecular, Cellular and Medical Aspects . 6th edition. In: Basic Neurochemistry: Molecular, Cellular and Medical Aspects . 6th edition .

94. Chen TT, Strahlendorf PW, Wyatt GR (1978) Vitellin and vitellogenin from locusts ( Locusta migratoria ). JBiolChem

95. Gaio ADO, Gusmão DS, Santos A V., et al (2011) Contribution of midgut bacteria to blood digestion and egg production in aedes aegypti (diptera: Culicidae) (L.). Parasites and Vectors. https://doi.org/10.1186/1756-3305-4-105 
96. Sudo N, Chida Y, Aiba Y, et al (2004) Postnatal microbial colonization programs the hypothalamic-pituitary-adrenal system for stress response in mice. J Physiol. https://doi.org/10.1113/jphysiol.2004.063388

97. Mazzoli R, Pessione E (2016) The neuro-endocrinological role of microbial glutamate and GABA signaling. Front. Microbiol.

98. De T Das, Sharma P, Thomas T, et al (2018) Interorgan molecular communication strategies of "Local" and "Systemic" innate immune responses in mosquito Anopheles stephensi. Front Immunol. https://doi.org/10.3389/fimmu.2018.00148

99. Chen A, Singh C, Oikonomou G, Prober DA (2017) Genetic Analysis of Histamine Signaling in Larval Zebrafish Sleep. eneuro. https://doi.org/10.1523/eneuro.028616.2017

100. Bushey D, Tononi G, Cirelli C (2015) Sleep- and wake-dependent changes in neuronal activity and reactivity demonstrated in fly neurons using in vivo calcium imaging. Proc Natl Acad Sci. https://doi.org/10.1073/pnas.1419603112

101. Cava F, Lam H, De Pedro MA, Waldor MK (2011) Emerging knowledge of regulatory roles of d-amino acids in bacteria. Cell. Mol. Life Sci.

102. Aliashkevich A, Alvarez L, Cava F (2018) New insights into the mechanisms and biological roles of D-amino acids in complex eco-systems. Front. Microbiol. 